San Jose State University

SJSU ScholarWorks

Master's Theses

Master's Theses and Graduate Research

1994

\title{
Functional fitness profile of older adults in select Santa Clara County senior and community centers
}

Ruth E. Haynes

San Jose State University

Follow this and additional works at: https://scholarworks.sjsu.edu/etd_theses

\section{Recommended Citation}

Haynes, Ruth E., "Functional fitness profile of older adults in select Santa Clara County senior and community centers" (1994). Master's Theses. 839.

DOI: https://doi.org/10.31979/etd.a2u4-eqhc

https://scholarworks.sjsu.edu/etd_theses/839

This Thesis is brought to you for free and open access by the Master's Theses and Graduate Research at SJSU ScholarWorks. It has been accepted for inclusion in Master's Theses by an authorized administrator of SJSU ScholarWorks. For more information, please contact scholarworks@sjsu.edu. 


\section{INFORMATION TO USERS}

This manuscript has been reproduced from the microfilm master. UMI films the text directly from the original or copy submitted. Thus, some thesis and dissertation copies are in typewriter face, while others may be from any type of computer printer.

The quality of this reproduction is dependent upon the quality of the copy submitted. Broken or indistinct print, colored or poor quality illustrations and photographs, print bleedthrough, substandard margins, and improper alignment can adversely affect reproduction.

In the unlikely event that the author did not send UMI a complete manuscript and there are missing pages, these will be noted. Also, if unauthorized copyright material had to be removed, a note will indicate the deletion.

Oversize materials (e.g., maps, drawings, charts) are reproduced by sectioning the original, beginning at the upper left-hand corner and continuing from left to right in equal sections with small overlaps. Each original is also photographed in one exposure and is included in reduced form at the back of the book.

Photographs included in the original manuscript have been reproduced xerographically in this copy. Higher quality 6" $\times 9$ " black and white photographic prints are available for any photographs or illustrations appearing in this copy for an additional charge. Contact UMI directly to order.

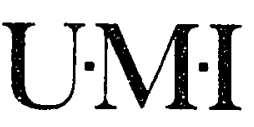

University Microfilms International

A Bell \& Howell Information Company

300 North Zeeb Road. Ann Arbor, MI 48106-1346 USA

$313 / 761-4700,800 / 521-0600$ 
- 
Functional fitness profile of older adults in select Santa Clara County senior and community centers

Haynes, Ruth Elaine, M.A.

San Jose State University, 1994 


\title{
FUNCTIONAL FITNESS PROFILE OF OLDER ADULTS IN SELECT SANTA CLARA COUNTY SENIOR AND COMMUNITY CENTERS
}

\author{
A Thesis \\ Presented to \\ The Department of Human Performance \\ San Jose State University \\ In Partial Fulfillment \\ of the Requirements for the Degree \\ Master of Arts
}

by

Ruth E. Haynes

August, 1994 
(c) 1994

Ruth E. Haynes

ALL RIGHTS RESERVED 
APPROVED FOR THE DEPARTMENT OF HUMAN PERFORMANCE

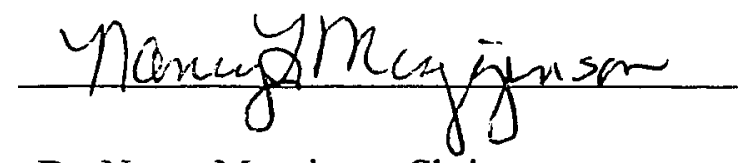

Dr. Nancy Megginson-Chair

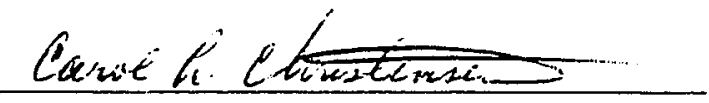

Dr. Carol Christensen

Comer flames

Jaunts Haynes

APPROVED FOR THE UNIVERSITY

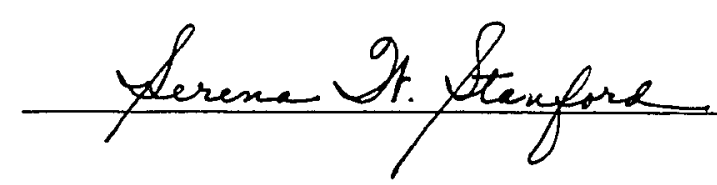




\begin{abstract}
FUNCTIONAL FITNESS PROFILE OF OLDER ADULTS IN

SELECT SANTA CLARA COUNTY SENIOR AND COMMUNITY CENTERS
\end{abstract}

by Ruth E. Haynes

Establishment of health-related fitness goals of older adults is essential in designing appropriate physical activity programs at various senior centers. The purpose of this project was to assess the fitness levels of older adults over age 60 years, utilizing the AAHPERD Functional Fitness Test Battery, in select Senior and Community Centers in the Santa Clara County area. There were 285 subjects (50 males and 235 females), aged 60 to 96 years, involved in this project who were tested according to the standards set forth in the AAHPERD Functional Fitness Test Battery. A reference profile were developed from the data, including percentile tables, based on the age and gender of the sample. It was the intent of this project to provide a functional fitness profile, with information pertinent to gender and age, for use by fitness instructors of older adults in the Santa Clara County area. By using the test battery and comparing scores to the functional profile, the fitness instructor can then address that an older adult's fitness strengths and weaknesses and provide ameliorative exercises. 


\section{ACKNOWLEDGMENTS}

I would like to thank my project committee, Nancy Megginson, Carol

Christensen, and Jim Haynes for helping me create this reference profile for older adults. I would also like to thank all the Senior and Community Centers who cooperated with me on the Functional Fitness Test Battery. A big thanks is given to my assistants and other people who helped me administer the Test Battery. Lastly, I would like to thank my husband and our daughter who have endured the many years I have devoted to this project. 


\section{TABLE OF CONTENTS}

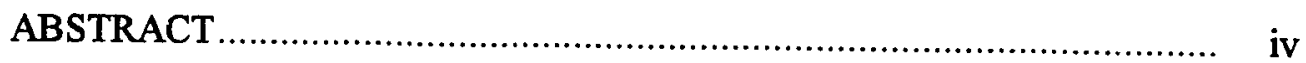

ACKNOWI.EDGMENTS ........................................................ v

TABLE OF CONTENTS ....................................................... vi

LIST OF TABLES .................................................................. ix

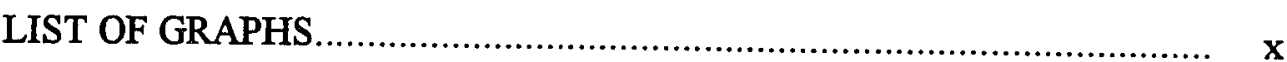

LIST OF FIGURES ..................................................................

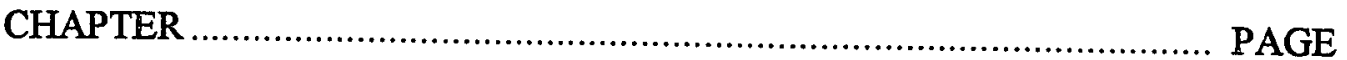

I. INTRODUCTION ...................................................... 1

Purpose of the Project ............................................. 3

Significance of the Project ........................................ 3

Definitions ......................................................... 4

Delimitations ....................................................... 5

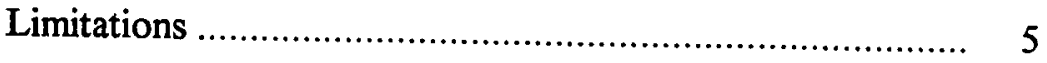

Assumptions ..................................................... 7

Summary ......................................................... $\quad 7$

II. REVIEW OF LITERATURE ......................................... 9

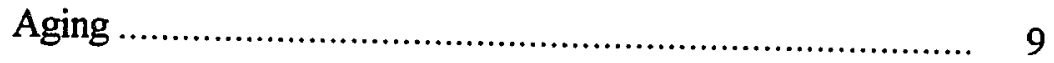


Fitness, Exercise, and the Older Adult.......................... 10

Fitness Assessment for Adults over 60 Years .................. 12

Summary ....................................................... 17

III. PROCEDURES ........................................................ 18

Selection of Subjects............................................. 18

Assistant Training ................................................ 20

PAR-Q Screening Device........................................... 20

Functional Fitness Test for Adults Over 60 Years ............. 21

Data Collection and Confidentiality .............................. 23

Statistical Analyses ............................................... 24

Summary ......................................................... 24

IV. RESULTS .............................................................. 26

PAR-Q Results ................................................... 26

AAHPERD Functional Fitness Test Battery Results.......... 27

Flexibility .......................................................... 30

Agility/Dynamic Balance ......................................... 31

Coordination....................................................... 32

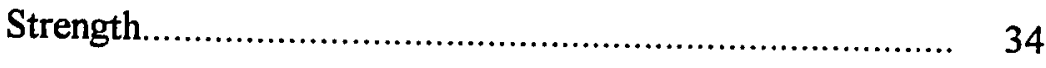

Endurance ......................................................... 35

Reference Profile ................................................... 37

Summary .......................................................... 37 
Test Battery Results and Discussion............................. 40

Reference Profile Data Results and Discussion................ 44

Dissemination of Reference Profile Data ........................ 45

Conclusions ........................................................ 45

Limitations ..................................................... 47

Recruitment Strategies.......................................... 47

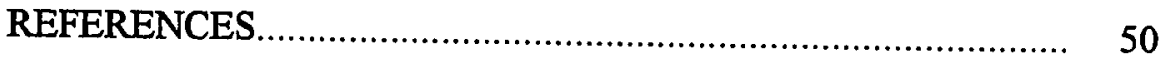

A

A. Informed Consent Form ..................................... 57

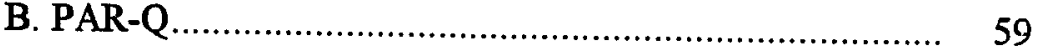

C. Test Description.................................................. 61

D. Data Form …................................................... 73

E. Senior and Community Centers ................................ 74 


\section{LIST OF TABLES}

TABLES

PAGE

1. Age Interval, Ranges, Means, Standard Deviations, and

Cases of Fitness Factor Performance by Gender.

2. Percentiles by Age Interval and Fitness Factor for Healthy Males

in Select Santa Clara County Senior and Community Centers............. 38

3. Percentiles by Age Interval and Fitness Factor for Healthy Females

in Select Santa Clara County Senior and Community Centers............... 39 


\section{LIST OF GRAPHS}

GRAPHS

PAGE

1. Flexibility Factor Performance...

31

2. Agility/Dynamic Balance Factor Performance.

32

3. Coordination Factor Performance..

33

4. Strength Factor Performance. 35

5. Endurance Factor Performance. 36 


\section{LIST OF FIGURES}

FIGURES

PAGE

1. Equipment Set-up for the Trunk/Leg Flexibility Test.................... 61

2. Chair Set-up for the Agility/Dynamic Balance Test...................... 63

3. Masking Tape Placement for the "Soda Pop" Coordination Test......... 66

4. Coordination Test Movement Sequence.................................. 67

5. Shaded area coverage for the "Soda Pop " Coordination Test........... 68 


\section{CHAPTER I}

\section{INTRODUCTION}

The United States can expect a continuous increase in the number and proportion of older people in its population. This older adult population will have grown from three million in 1965 to a projected thirty-two million by the year 2000 . Fifteen to twenty percent of the total population by the year 2000 will be comprised of older adults (Koss, 1989; Spirduso, 1985). The fastest growing segment of the older population is women who are 74 years or older. Because of the growing number of older adults, society is becoming more aware of the increased cost of the elderly, its potential problems and, finally, the realities of aging (Spirduso, 1985). Ninety- five percent of the people over the age of 65 live on their own, with friends, or in board and care homes (National Institute on Aging, 1985). Health programs aimed at this population have been successful in encouraging people to stop smoking, to improve dietary habits, and to reduce stress. Also, adult exercise programs have helped people to become more physically fit (Paffenberger, Hyde, \& Wing, 1986; Isaacs, 1989).

As the older population grows, so will the need for physical and health-related services for this group. The professions of health, physical education, recreation, and dance will be challenged to expand and address the needs of a changing older society. 
The value of exercise to the health of the older adult has been established by various professionals in the field of physical education (Kasch, Wallace, Van Camp, \& Verity, 1988; Paffenberger et al., 1986; Shephard, 1985; Smith \& Zook, 1986). Physical fitness assessment is an integral part of the physical education process. It is especially important for the older adult since there is so much heterogeneity in the functional levels of this population (Lasko, 1988). A fitness assessment can: (1) establish the older adult's current level of performance, (2) allow the instructor to prescribe feasible, safe, beneficial, individualized exercise goals, and (3) upon post-testing, provide the older adult with a record of progress or maintenance (Adrian, 1989; Lasko, 1988; Petray, Blazer, Lavay, \& Leeds, 1989). As older adult exercise programs are developed, appropriate measurement techniques need to be established in order to assess the fitness level of the older adult. Traditionally, these measurements have been evaluated in a clinical setting using sophisticated equipment such as treadmills and bicycle ergometers, but this situation is not readily available to the general population or feasible to the physical education practitioner. To meet this need, a field test was developed by the American Alliance for Health, Physical Education, Recreation, and Dance (AAHPERD) to assess the functional fitness level of older adults over age 60 (AAHPERD, 1990). At this time, no national norms have been established 
(W. Osness, personal communication, November 12, 1992). Population-based norms have played a dominant role in the fitness level interpretation of individuals and groups. The health-related fitness norms by AAHPERD for children are population-based (Ross, Pate, Delpy, Gold, \& Svilar, 1987) and are useful in two ways. First, such norms constitute a description of the current status of a population in terms of the variables observed. Second, when the tests are given again, the resulting normative data provides a base for tracking change in the population over time.

\section{Purpose of the Project}

The purpose of this project was to assess older adults in select Santa Clara County Senior and Community Centers to obtain a profile of the functional fitness levels in this population. The subjects were tested according to the standards set forth in the AAHPERD Functional Fitness Test Battery ( AAHPERD, 1990). More specifically, the participants were tested on five parameters: flexibility, agility/dynamic balance, coordination, strength, and endurance.

\section{Significance of the Project}

It was the intent of this project to provide a functional fitness profile, with information pertinent to gender and age, for use by physical educators, fitness 
instructors, activity directors, and other health-related professionals. Fitness

professionals can, then, individualize their older adult exercise programs based on specific needs reflected by their clients' scores on the functional fitness test. Secondly, the instructor will be able to determine an older adult's weaknesses and strengths by comparison of scores with a regional reference or profile. An individualized program can then be prescribed to address that individual's weaknesses.

\section{Definitions}

Agility- the physical ability which enables an individual to rapidly change body position and direction in a precise manner (Eichstaedt \& Kalakian, 1993).

Coordination- the behavior of two or more joints in relation to each other to produce skilled activity (Schmidt, 1988).

Dynamic Balance- the maintenance of the body's equilibrium while the body is in motion (AAHPERD, 1985).

Endurance- the ability of an individual to sustain low intensity exercise, such as walking over an extended period of time (Kisner \& Colby, 1990).

Flexibility- the range of motion possible about a given joint or series of joints ( Prentice \& Bucher, 1988). 
Functional Fitness- the physical capacity of the individual to meet ordinary and unexpected demands of daily life safely and effectively (Osness, 1989).

Older Adult- adults 60 years of age and up who passed the Physical Activity Readiness Questionnaire (PAR-Q) for the purposes of this project (Reid \& Thompson, 1985).

Strength- the maximal capacity of a muscle or muscle groups to exert force against a resistance (Sienna, 1989).

\section{Delimitations}

The project was delimited to an older adult population, sixty-plus years, who are served by Senior Centers and Community Centers in Santa Clara County. The sample was drawn from healthy older adults, according to the Physical Activity Readiness Questionnaire (PARQ-Q) (American College of Sports Medicine, 1986). The functional fitness assessment for adults over age 60 was administered to all who qualified.

\section{$\underline{\text { Limitations }}$}

Each participant was expected to perform to one's capacity without discomfort or unusual risks. There might be a psychological factor related to one's intensity in performing the specified activities which may affect the end result. Other 
factors may include pharmaceutical and anatomical factors which may influence the results. For example, a very high percentage of persons sixty years and older are on some type of prescribed or self-prescribed medication. The researcher had to determine whether the medications would affect the results of the assessment. If there was not a contraindication, the test was to proceed. This problem can be found in almost any performance test currently in use (Osness, 1989).

Most older adults have some type of joint problem and have different pain thresholds. If movement of a mobility-reduced body part was necessary, the collected data may reflect restricted movement due to pain as opposed to the desired physical function (Osness, 1989). Environmental conditions such as the time of year, outside temperature, and inside temperature may influence the end result data (Corbin \& Metal-Corbin, 1990). However, all of these factors are involved in the assessment of the physical condition of the young person as well as the older person. One must exercise caution and control as the data is collected and reported. The above factors are important, but it is also implied that these same factors would be involved in the development of an exercise prescription for the older adult. 


\section{Assumptions}

The older adult was clinically free of diagnosable cardiovascular, pulmonary, or other disorders that might contraindicate their participation in this study according to the AAHPERD Fitness Task Force (1988). Also, the older adult will perform the various test items to the best of one's ability. Parameters listed and test items used were selected because each was determined to relate to general fitness.

\section{Summary}

The value of exercise has been well established by various health professionals. An evaluation process has been developed by AAHPERD to test the functional fitness level of older adults aged $60+$ years. This project was undertaken to ascertain the fitness levels of older adults who participate in activities and classes in select Senior and Community Centers in the Santa Clara County area. Such normative functional fitness data would be a valuable addition to objectively compare and evaluate a person's fitness level. Areas of weakness could, then, be identified and remediation and/or emphasis may be made through the use of an individualized exercise program. The fact that an older individual can expect a decline in most physical functions over time creates a need to assess one's fitness level again from time to time. As an individual ages, it becomes more important to compare one's fitness 
level with a finite age range and one's own gender. It is the functional age that is important to the quality of life. 


\section{CHAPTER II}

\section{REVIEW OF LITERATURE}

In this review of literature, several factors will be discussed. Various aspects of aging will be examined followed by fitness and exercise in the older adult. Finally, assessment of older adult fitness will be discussed. These sections will be followed by a chapter summary.

\section{$\underline{\text { Aging }}$}

The process of aging is complex, which include biological, psychological, sociological, and behavioral changes. Nobody knows exactly the process of aging or why it runs different courses in different people. What is known is that our bodies undergo changes with advancing age. These age-related changes do not happen to everyone or at a predicable rate (Flieger, 1988). Various physiological systems seem to decline with age, and thus, represent an accumulation of insults and gradual deterioration in the body. This is reflected in the gradual loss of the body's ability to adapt to stress (Flieger, 1988; Kenney, 1982; Smith \& Zook, 1986).

Aging results from the decline of various physiological functions that progress at differing rates. There is a gradual rather than an abrupt decline in functions such as cardiac output, kidney and pulmonary functioning, muscle strength, 
and endurance, and flexibility (Brody, Kleban, \& Oriol, 1985). It should be noted that not all physiological functions will demonstrate signs of declining.

There is also a greater variety of health and development differences among older individuals than among any other age group. While every three year old can be predicted to experience certain developmental tasks, there is wide variety in the physical behavior of 65 year olds. Some are in good health, employed, and performing productive work. Others are retired and are in good or poor health while some have died before reaching the age of 65 (Koss, 1989; McLean, 1992).

Many physical changes in older individuals that are mistakenly attributed to aging may be actually due to inactivity, or in other words, being physically unfit. The goal of remaining physically active with advancing age is to delay the declines in functional capacity with aging (Shepard, 1978, 1985).

\section{Fitness, Exercise, and the Older Adult}

Physical fitness as defined by Clarke (1977) states: "Physical fitness is the ability to carry out daily tasks with vigor and alertness, without undue fatigue, and with ample energy to enjoy leisure time pursuits and to meet unusual situations and unforeseen circumstances" (p. 2). Even though this broad definition was stated in 1977, it still applies in today's society. This definition closely relates to the functional 
fitness definition established by the AAHPERD Fitness Task Force (Osness, 1989) which is the "physical capacity of the individual to meet ordinary and unexpected demands of daily life safely and effectively" (p. 64). Thus, the primary goal of exercise programs for older adults should be to improve their ability to take care of themselves and to feel better during the later years of life. Simple activities of daily living require cardiovascular endurance, flexibility, muscle strength, and muscle endurance (Fiatorone \& Evans, 1990; Skinner, 1987). Therefore, an older adult needs to improve cardiovascular endurance, increase muscle strength and muscle endurance, maintain or improve flexibility, coordination, and balance for activities of daily living (Skinner, 1987).

Nearly $80 \%$ of all older adults have some chronic disability (arthritis, hypertension, coronary heart disease, obesity, etc.) that limits or affects their participating in exercise and enjoyment of life (Koss, 1989). What can exercise do to prevent, postpone, or ameliorate these problems and thus improving their quality of life and decreasing the chronic disabilities with their associated medical and personal costs? Regular exercise cannot retard the fundamental process of aging; but it can offer the equivalent of 10 to 20 years of rejuvenation, countering a deterioration in cardiovascular and muscular function. (Shepard, 1985). Smith and Zook (1986) have 
indicated that as much as fifty percent of physiological decline is related to disuse and that a high level of physiological function can be maintained into the later years of aging with regular physical exercise. Generally exercise is a safe activity for most individuals, but the American College of Sports Medicine (1986) recommends that aủults have at least some screening prior to starting an exercise program by means of a health questionnaire or medical examination before an exercise prescription is followed.

\section{Fitness Assessment for Adults Over 60 Years}

Physical fitness assessment is a integral part of the physical education process.

It is especially important for the older adult since there is so much heterogeneity in the functional levels of this population (Lasko, 1988). A fitness assessment can: (1) establish the older adult's current level of performance, (2) allow the instructor to prescribe feasible, safe, beneficial, individualized exercise goals, and (3) upon posttesting, provide the older adult with a record of progress and/or maintenance (Adrian, 1989; Lasko, 1988; Petray et al., 1989).

There have been no standardized questionnaires or diaries in which physical activity characteristics have been uniformly monitored. LaPorte, Montoye, and Caspersen (1985) identified over 30 different studies which assessed physical activity 
monitoring in which different types of questionnaires and monitoring devices were used. So it has not been possible to meaningfully compare the results of various studies that used different techniques to assess physical activity (Laporte, Montoye, \& Caspersen, 1985).

There have been numerous studies in the past decades that suggest a relationship between physical activity and mortality (Blair, Brill, \& Kohl, 1989). The Alameda County Study, in the Oakland, California area, has followed nearly 7,000 male adults since 1965 (Kaplan, Seeman, Cohen, Knudsen, \& Gumalmik, 1987). All-cause mortality has been positively associated with smoking, physical inactivity, being overweight, and snacking between meals which are supposedly adverse health behaviors. This study further demonstrated that physical inactivity showed a relative risk of 1.38 for all-cause mortality.

The Harvard Alumni Study by Paffenberger et al. (1986) followed nearly 17,000 male Harvard alumni for up to 16 years to measure all-cause mortality. Baseline physical activity status was answered by a questionnaire and from this data total energy expenditure was estimated. The most active (60-69 years) and (70-84 years) had a 50 percent risk of dying prematurely compared with the least active group (50-59 years) which had a 65 percent risk of dying prematurely. 
Morris, Everitt, Pollard, Chase, and Semiing (1980) studied 18,000

middle-aged office workers in Great Britain for all-cause mortality. The differences in death rate between active and sedentary men increased with age. Vigorous exercise seemed to offer more protection in the older men than in the younger men who did not exercise

The Honolulu Heart Study was conducted in 1965 involving 8,000 men, aged 45 to 70 years, in which coronary heart disease had developed and which resulted in 444 heart attacks. Physical activity was assessed and it was reported that for men aged $65-70$ years, the relative risk of developing heart disease was $41 \%$ to those who were active in 1965 than those who were inactive (Donahue, Abbott, Reed, \& Yano, 1988).

These four studies showed an inverse relationship between mortality and physical activity in older men. There was one factor that was consistent in all four studies--physical activity. Each of the studies assessed physical activity in four different ways. One was "active" in the Alameda study if "sometimes active" was marked. In the Harvard study, physical activity was assessed by questionnaire, and from this data, physical activity in kilocalories per week was estimated. One was considered "active" if one participated in physical activity which was calculated to be 
over $2,000 \mathrm{kcal}$ per week. In the British study, one was "vigorous" if one did physical activity at least five minutes per day. The Honolulu study recorded activity in a twenty-four hour period. There was a wide range of sensitivities as to what constituted physical activity, but the inverse relationship between mortality and physical activity is consistent and strong. The problem with the relationship between physical activity and health status is the lack of easily administered, valid, and reliable measures of routine activity. Measurement tools are needed to establish baseline activity patterns, to accurately measure changes outside of supervised settings, and to design exercise programs that are effective yet safe (Haskell, 1989).

Population-based norms have played a dominant role in the interpretation of fitness levels of individuals and groups. The health-related fitness norms for children established by AAHPERD are population-based (Ross et al., 1987). This can be useful in two ways. First, such norms constitute a description of the current status of a population in terms of the variables measured. Second, when the tests are given again, the resulting normative data provides a base for tracking change in the population over time.

Appropriate measurement techniques have not been established until now to test whether an exercise program is valid for an individual with complicating 
conditions such as aging. These evaluations can be done in a clinical setting with sophisticated equipment and medical personnel, but this choice is not available to the larger population. There was a need for a more effective field test for health status evaluations of the older adult (Osness, 1989).

In 1986, AAHPERD appointed a committee to develop an appropriate assessment technique for older adults. In 1990, a list of parameters were identified for use in this test. The list included: (1) agility/dynamic balance, (2) endurance, (3) flexibility, (4) strength, and (5) coordination. The preliminary data were collected from various sites and evaluated to establish entry norms. A system of feedback is being developed to continually update the norms and to provide a more meaningful comparison of a given individual to one's peers. The norms will be constructed through the analysis of six to seven thousand older adults distributed evenly among the various older adult groups. The population-based functional fitness norms can be appropriately used by physical educators in several ways: (1) it allows the status of any group of older adults to be that of the "typical" older adult, (2) percentile norms can be used as a general guide in assigning qualitative ratings, and (3) valid, normative data can be used as a basis for comparison of selected subgroups with the population at large (Ross et al., 1987). 


\section{Summary}

The evolution of testing the fitness level of older adults coincides with the increase in research evaluating the effects of exercise and training on various fitness components in older adults (Compton, Eisenman, \& Henderson, 1989). However, gerontological research regarding exercise and aging is still in its infancy. Research of the older adult is difficult because of the inherent problems in regards as to what losses in human functioning are due to aging and what losses are due to disease. It is very rare that a researcher can assemble individuals over the age of 65 who are free of disease (Isaacs, 1989). As our own understanding of various age-related diseases improves, the probability exists that exercise might play a role in alleviating symptoms and/or provide some protection from disease. The older adult remains the least active of our population, so substantial behavioral research is required that will keep large segments of the aging population physically active into their 70's and 80's (Haskell, 1989). In the next chapter, procedures and methods of the AAHPERD Functional Fitness Test Battery are presented along with project information concerning the methods for selection of subjects, training of assistants, PAR-Q screening device, data collection, and confidentiality. Statistical analyses are also examined. 


\section{CHAPTER III}

\section{PROCEDURES}

The purpose of this project was to assess the fitness levels of older adults

over the age of 60 years in select Santa Clara County Senior and Community Centers, using the AAHPERD Functional Fitness Test Battery to obtain a functional profile of this population. This chapter describes the selection of subjects, training of assistants, PAR-Q screening device, data collection, and confidentiality concerning the project. The procedures and methods of the AAHPERD Functional Fitness Test Battery are also presented along with statistical analyses of project data.

\section{Selection of Subjects}

The subjects, aged $60+$ years, were selected from older adult volunteers at 12 Senior and Community Centers in 5 cities in the Santa Clara County area. There were 285 participants, 50 males and 235 females, involved in this project. Attempts were made to contact all the Senior and Community centers in the Santa Clara County area. Letters were written to all of these sites with a description of the test and what was required of the center for its participation. The researcher made a videotape of the AAHPERD Functional Fitness Test Battery and showed it to the Senior Coordinators of the City of San Jose and to the Senior Coordinating Council of Santa Clara/ San 
Mateo County. A copy of the Functional Fitness Test Battery was also given at these meetings and cooperation/participation was asked to let the researcher use these centers as testing sites. Out of 19 Senior and Community Centers, 12 centers were cooperative in letting the researcher use their facilities. The project was explained in detail at each site and the researcher physically visited each site to set up a date and time for testing. The centers were cooperative in publicizing the fitness assessment in their monthly newsletter and most of the sites put up posters that the researcher provided. The researcher also visited various activities at each center, such as the senior nutrition lunch program and bridge club, to explain the assessment and to tell the participants when it was going to be conducted at their site. The researcher also visited various classes at each center, such as computer classes and exercise classes, to explain the assessment.

At the appointed day and time, the researcher and her assistants arrived to administer the Functional Fitness Test Battery according to the standards set forth by AAHPERD. The subjects were asked to wear comfortable clothing, including shoes in which they could walk. The subjects were given warm-up exercises for ten minutes in order to perform the Functional Fitness Test more efficiently. 


\section{Assistant Training}

Adapted Physical Education student assistants were trained in each aspect of the test by the researcher so that the administration of the test items ran according to the AAHPERD protocol. The assistants attended two, one-hour training sessions on the aspects of administering the test as stated in the test booklet (AAHPERD, 1990). Depending on the site, there were two to four assistants, plus the researcher, to conduct the Functional Fitness Test Battery.

\section{PAR-Q Screening Device}

The Physical Activity Readiness Questionnaire (PAR- Q) was used as a screening device for the subjects involved in this study. It has been used extensively in Canada by fitness professionals to identify almost all individuals for whom it might be dangerous to participate in sub-maximal exercise testing and as a general screening device (American College of Sports Medicine, 1986; Reid \& Thompson, 1985). Two other questions were added to ascertain the current fitness level of the subject: whether the individual participates in an aerobic activity at least three times a week or does strength training at least two times a week. 


\section{Functional Fitness Assessment for Adults Over 60 Years}

The parameters to be measured by the AAHPERD Functional Fitness Test for

Older Adults included: body composition, flexibility, agility/dynamic balance, coordination, muscular strength, and endurance.

Body composition was measured by ponderal index which involves the relationship between height and weight. The subjects were to have their height and weight taken on the day of testing using a calibrated scale and a measuring tape on a wall. The use of anthropometric measurements was discarded because of the need of specific equipment and techniques. In addition, the formulas that use this information to project body fat have not been shown effective for older populations (Corbin \& Metal-Corbin, 1990).

Flexibility was evaluated by the Sit and Reach test which measures the flexibility of the lower back and upper leg. The Sit and Reach test was selected because it is a reasonable indicator of total body flexibility in the normal older adult (AAHPERD Fitness Task Force, 1988). The procedure for this test item was developed to use a yard stick or measuring tape to avoid the need for specific equipment, such as the sit and reach box, which may not be available in a field setting (Corbin \& Metal-Corbin, 1990). 
Agility/dynamic balance was measured using a new test item (chair agility) involving total body activity. It involves straight ahead movement, change of direction, and changing body position. The test closely relates to the functional movement of the older individual in daily life situations and also provides for a quantitative assessment of this ability. It is the most comprehensive of all test items used in the test battery (Corbin \& Metal-Corbin, 1990).

The 'soda pop' coordination test item also relates to daily function and concentrates on the neuromuscular efficiency of the arms and hands. It is a test involving the use of soda pop cans that are turned upside down and rightside up over a specified mark. It is a practical test and one that has good reproducibility as well as finite measurement potential.

Muscular strength was considered an important component of the test battery. The measurement of strength also included an endurance factor using the number of repetitions through a range of motion. The measurement involved upper body but also has been shown to be a good predictor of total body strength of the older individual (AAHPERD, 1990). This test was chosen by the AAHPERD Ffitness Task Force (1988) because it was more quantifiable than some of the other field test 
for dynamic strength that are dependent on body weight and moving the body through space (Corbin \& Metal-Corbin, 1990).

The endurance test item, the Walk Test, provides a functional assessment of walking ability in older adults. Its validity is moderate but comparable with other walk/run tests based solely on time (AAHPERD, 1990). The Walk Test may be administered in any open, well-lighted areas with an appropriate surface (even and non-slippery). For a complete description of the test items, procedures, and special considerations to be followed, refer to Appendix C.

\section{Data Collection and Confidentiality}

Each subject was instructed to sign an informed consent form for participation in the project as outlined by the San Jose State University Human Subjects Review Board. In order to maintain confidentiality, each site was given a letter followed by a number for each subject. An example would be: if John Smith was Subject 1 who was tested at site A-- his code would be A1. This letter and number was put on the data collection sheet for each subject. The researcher was the only individual who had access to this information so the confidentiality of each subject was maintained. 


\section{Statistical Analyses}

Data were categorized according to gender and five-year age intervals, such as 60-64 years, 65-69 years and so on. Means, standard deviations, ranges, and percentiles were determined relative to these independent variables. A reference profile was then developed, including percentile tables, outlining these results. Data were analyzed on SPSS computer program at the San Jose State University Computer Center. The percentile tables, from 10 percent to 90 percent, were developed from the data gathered from this project. The data will also be utilized to assist in establishing national norms for the Functional Fitness Test Battery for Adults Over Age Sixty (AAHPERD, 1990).

\section{$\underline{\text { Summary }}$}

The subjects in this study were healthy older adult subjects who volunteered at selected Senior and Community Centers in the Santa Clara County area. There were 285 ( 50 male and 235 female) subjects in this study who were considered healthy by guidelines set forth by the PAR-Q Screening Device (ACSM, 1986) and Functional Fitness Test Battery (AAHPERD, 1990). A study of the test items had previously been conducted a small number of subjects demonstrating their reliability and statistical validity (Osness, 1989). Preliminary testing was done to establish the 
practicality of the test in a field situation, provide feedback on the range of discrimination among given age and sex groups, establish preliminary norms, and determine the population that this test procedure can serve (AAHPERD iitness Task Force, 1988; W. Osness, personal communication, November 12, 1992). 


\section{CHAPTER IV}

\section{RESULTS}

The purpose of this project was to ascertain the fitness levels of older adults over age 60 years in select Santa Clara County Senior and Community Centers using the AAHPERD Functional Fitness Test Battery to obtain a functional reference profile for this population. This chapter discusses the results of PAR-Q and the AAHPERD Functional Fitness Test Battery according to the test item and each gender. The results of each test item is reported with an explanation regarding the findings. This is followed by a summary of the results.

\section{$\underline{\text { PAR-Q Results }}$}

The Physical Activity Readiness Questionnaire (PAR-Q) was used as a screening device for the subjects involved in this project. All of the volunteers who decided to participate passed the PAR-Q. Two questions were added to the PAR-Q for the purposes of this project. One question was, "Do you participate in an aerobic activity at least three times a week?" Fifty-four and 61 percent of males and females, respectively, reported positively (yes) to this question. The second question was, "Do you strength train at least two times a week?" Twenty-four and 17 percent of males and females, respectively, responded positively to the strength training question. 


\section{AAHPERD Functional Fitness Test Battery Results}

Data were categorized according to gender and five-year age intervals. Means, standard deviations, ranges, and percentiles were determined relative to these independent variables. Data were analyzed on SPSS computer program at the San Jose State University Computer Center. Only data from 60-79 years of age for males and from 60-84 years of age for females were considered for the results due to the small number of participants in the upper age intervals, but the data for the $80-89$ year old range for the males and the 85-99 year old range for the females are reported in Table 1. Due to the small number of male subjects in each age interval, the results may not accurately represent the fitness levels of male adults over 60 years of age.

The AAHPERD test items are statistically independent from each other. Each of the test items was presented individually so the subjects could choose whether or not to participate. For example, some subjects chose not to participate in the strength test item due to weak grip strength resulting from arthritis. Therefore, as reflected in Table 1, there exists unequal number of subjects in each gender and age interval. 


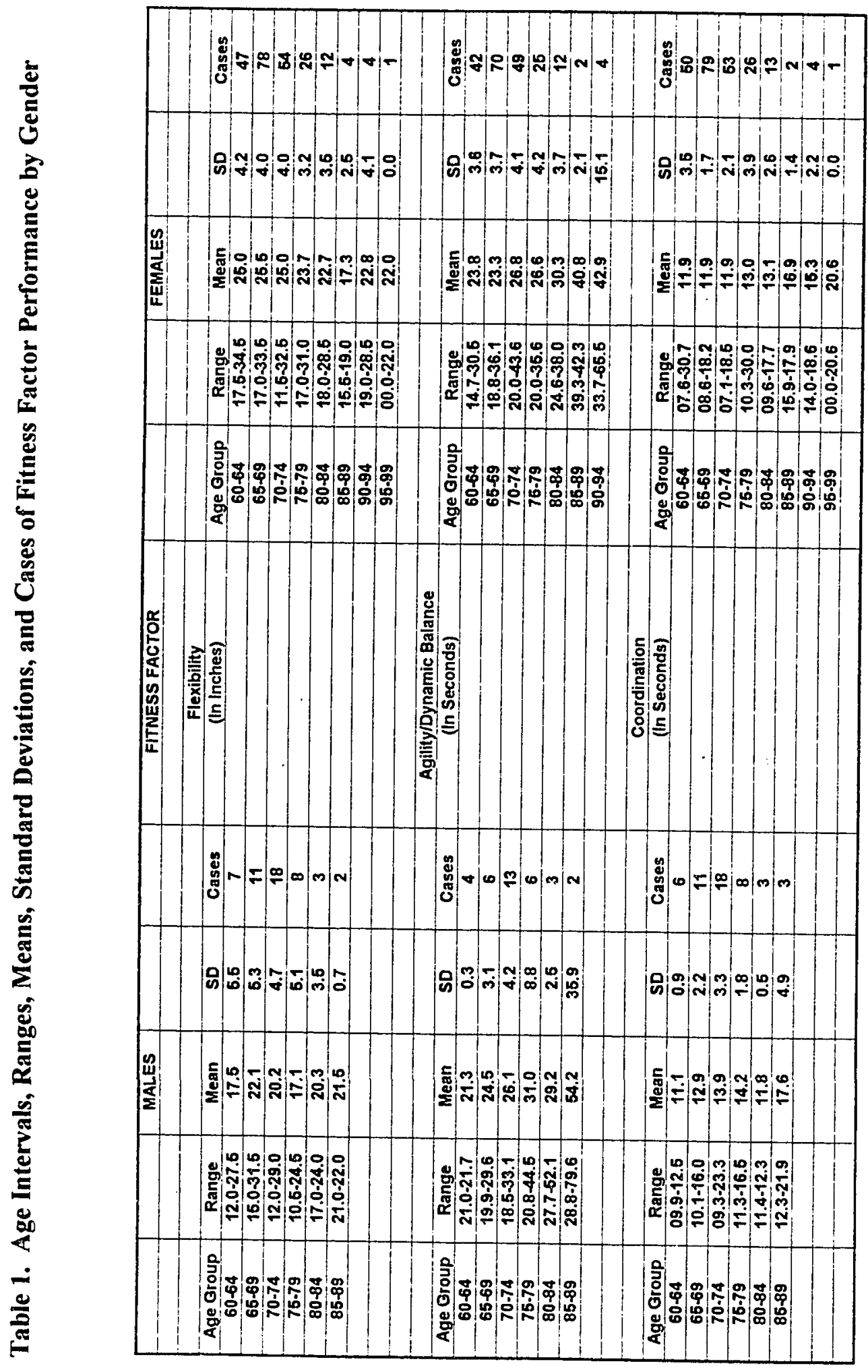




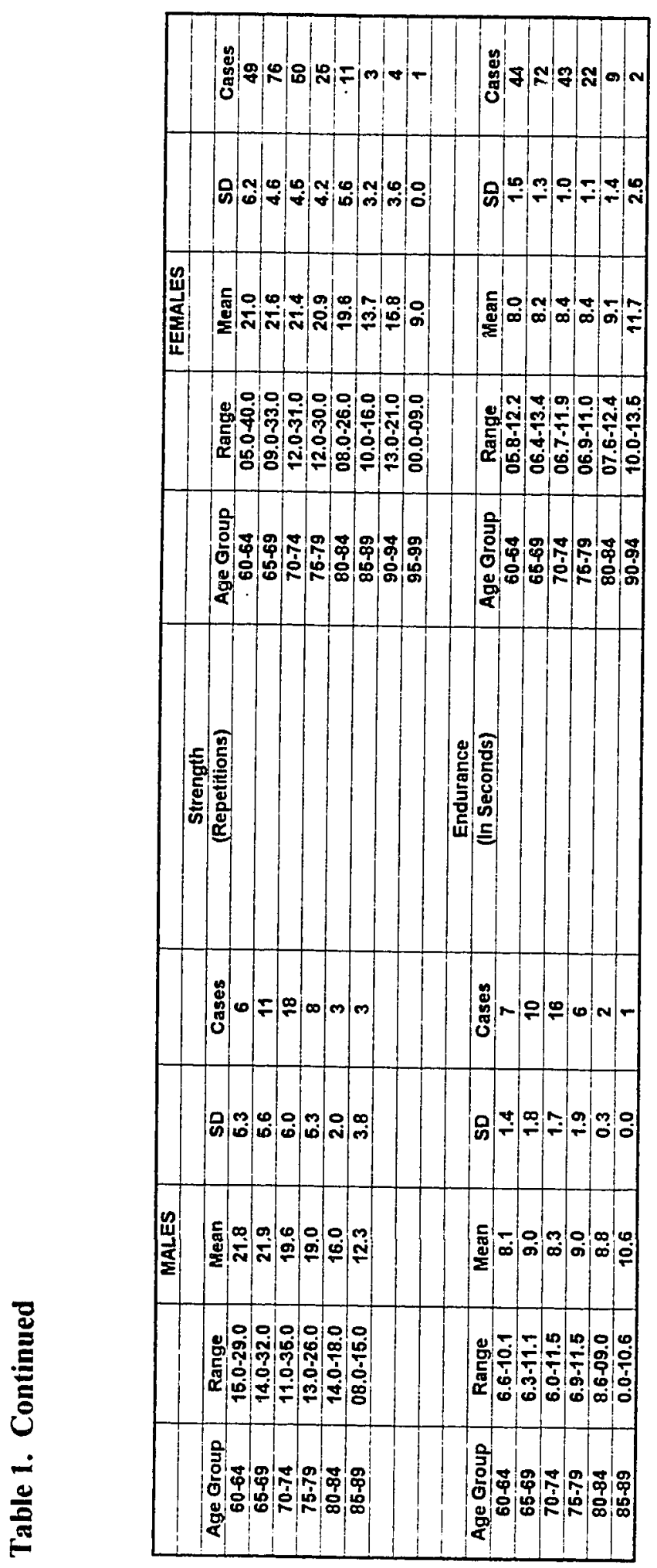




\section{Flexibility}

Flexibility was evaluated by the Sit and Reach test item which measures the flexibility of the lower back and upper leg. This is a reasonable indicator of total body flexibility in the normal older adult according to Corbin and Metal-Corbin (1990). This procedure was developed using a yard stick or measuring tape to avoid the need for specific equipment that may not be available in a field setting. Overall, as seen in Graph 1, male subject flexibility was less than that of the female subject at every age interval. The male subject's flexibility increased and decreased across the age intervals as shown in Graph 1 and Table 1. As reported in Table 1, age group interval 60-64 showed a lower mean than the upper age intervals of 65-69 and 70-74. This may have been due to the low number of male subjects at this age interval. The standard deviations (range $=4.7-5.5$ ) were approximately the same for each interval.

As shown in Graph 1 and Table 1, the female subjects showed little decline in flexibility across the age intervals until the 75-79 age interval. From the 75-79 age interval, there was a notable decline in flexibility in the upper age groups. The standard deviation for each age interval ranged from $3.2-4.2$ inches. 


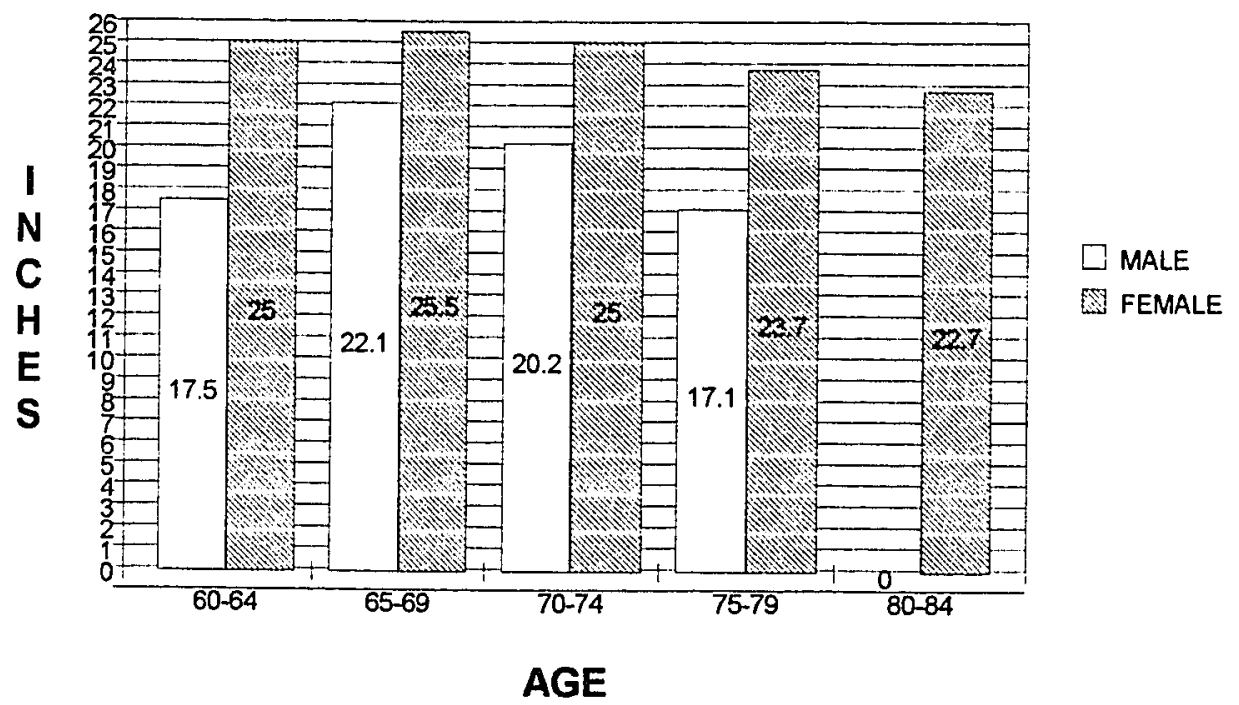

Graph 1. Flexibility Factor Performance.

\section{Agility/Dynamic Balance}

Agility/dynamic balance was measured using a new test involving total body activity called the Chair Agility test item. It involved straight ahead movement, change of direction, and changing body position. The test closely relates to the functional movement of the older individual in daily life situations. As shown in Graph 2 , the male subjects are reported to be faster than the females in all age intervals, except in the 75-79 and 65-69 age intervals. Again, caution should be noted in the reporting of these means for male subjects as three age intervals had six or less cases in each.

There appeared to be an increase in times for the Agility/Dynamic Balance Test as age level increases for male and female subjects. Standard deviation ranges were $.3-8.8$ 
and $3.6-4.2$ seconds for male and female subjects, respectively. As adults get older, it is important for them to maintain their mobility and as shown in these scores, one appears to lose the ability to more efficientiy or one exhibits more caution while moving around obstacles.

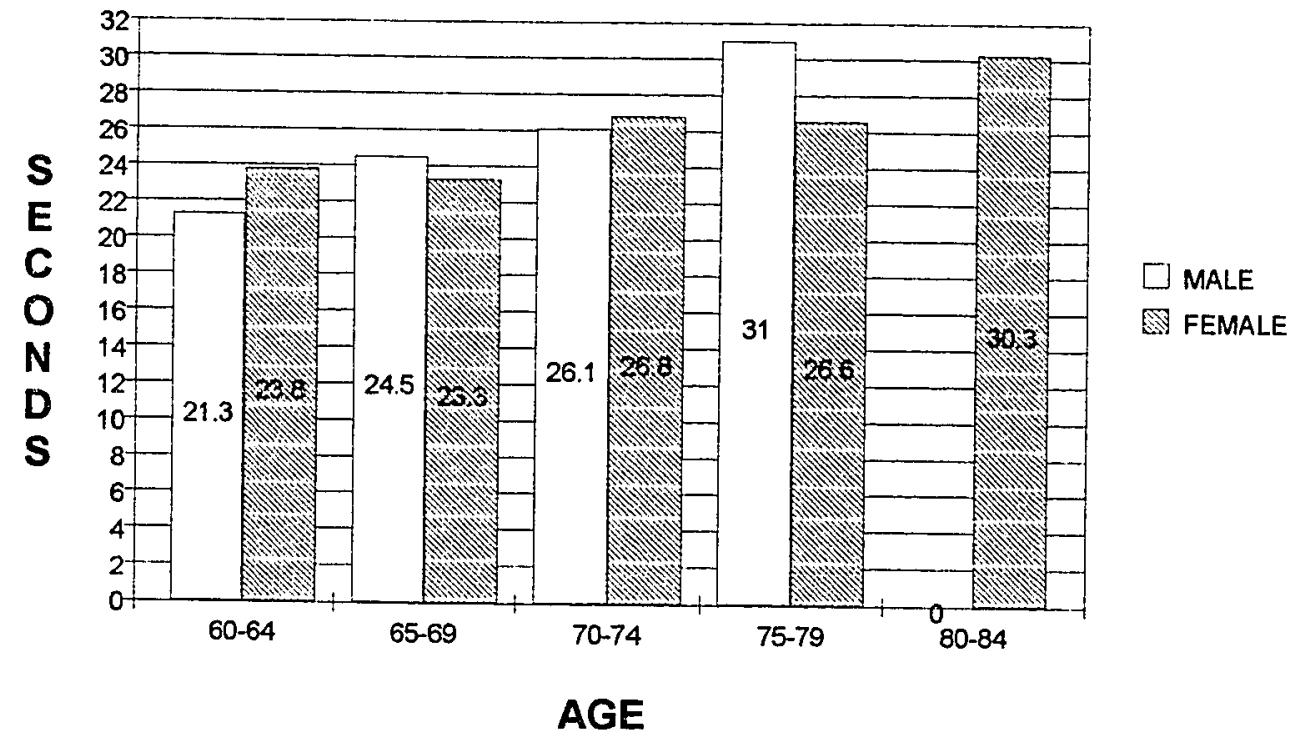

\section{Graph 2. Agility/Dynamic Balance Factor Performance.}

\section{$\underline{\text { Coordination }}$}

Coordination is related to daily function and concentrates on the neuromuscular efficiency of the arms and legs according to Corbin and Metal-Corbin (1990). A test was created by the AAHPERD Fitness Task Force (1988) called the 'Soda Pop' Coordination item which measured the neuromuscular efficiency of the arms. As shown in Graph 3 and Table 1, the male subjects showed an increase in the time 
needed to complete the task in the Soda Pop Coordination Test across the age intervals. There was inconsistency in the standard deviations (range $=.47-4.99$ ) due to the differing ranges of the scores and the number of subjects in each age interval.

The female subjects showed consistent means for the first three age intervals with a decline in performance in the 75-79 and 80-84 year age intervals. The standard deviations (range $=1.4-3.9$ ) were not similar due to the range of scores in each age interval. There appears to be an increase in performance time in the coordination test and, thus, a decline in neuromuscular efficiency as one grows older.

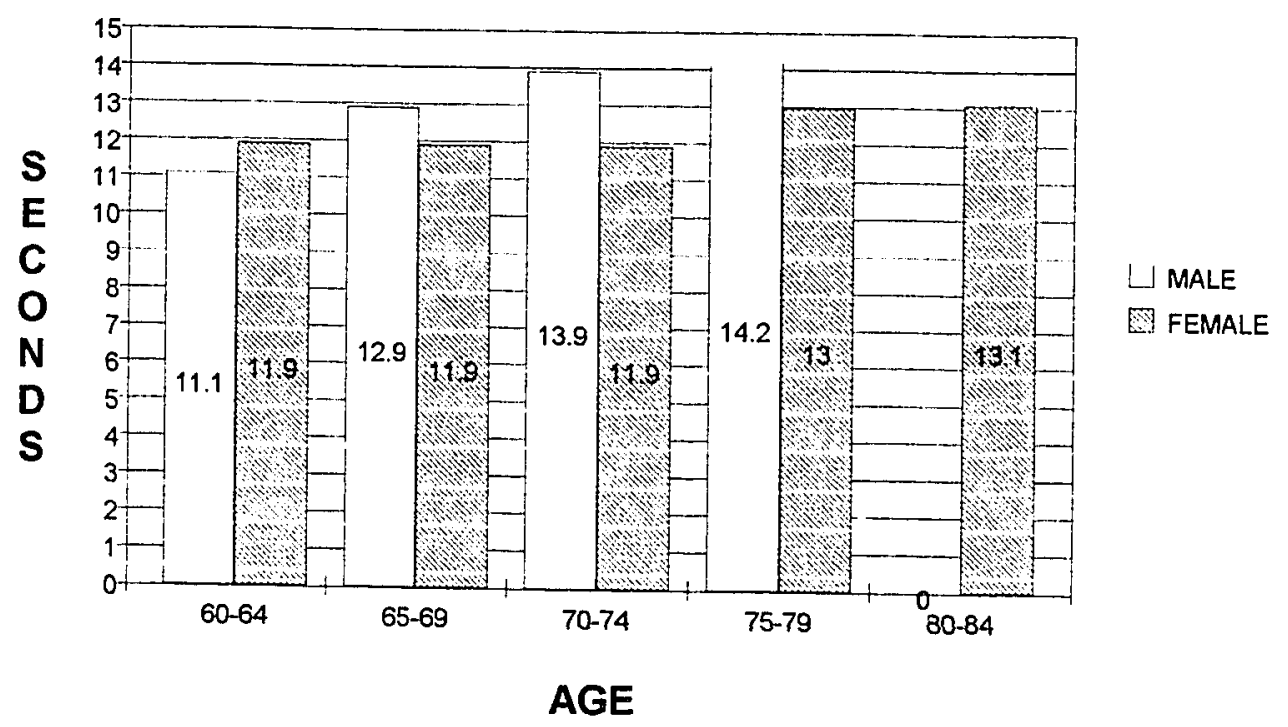

\section{Graph 3. Coordination Factor Performance.}




\section{Strength}

An important component of the test battery is the measurement of strength which was measured by the number of arm curis the subject could do in thirty seconds. It also included an endurance factor using the number of repetitions through a range of motion. The measurement involved the upper body but also has shown good predictability of total body strength of the older individual (Corbin and Metal-Corbin, 1990).

As shown in Graph 4, there was a slight decrease in strength over the age intervals in the males more than the females. For the males, as shown in Table 1, there was a wide range of scores for each age interval; thus the standard deviations were high (range $=5.3-6.0$ ). The first two age intervals had similar means and there was a decline in the following age intervals.

According to Table 1, the female subjects had relatively similar means across the age intervals until the $80-84$ age interval. The standard deviations (range $=4.2-6.2$ ) across the age intervals were dissimilar due to the range of scores within group. It was expected that the female subjects would have more of a decline in strength due to age, but this was not the factor. It may be due to the daily activities of living involving 
strength which kept their scores similar across the age intervals. The male subjects showed a decline in strength as expected but not until the 70-74 age interval.

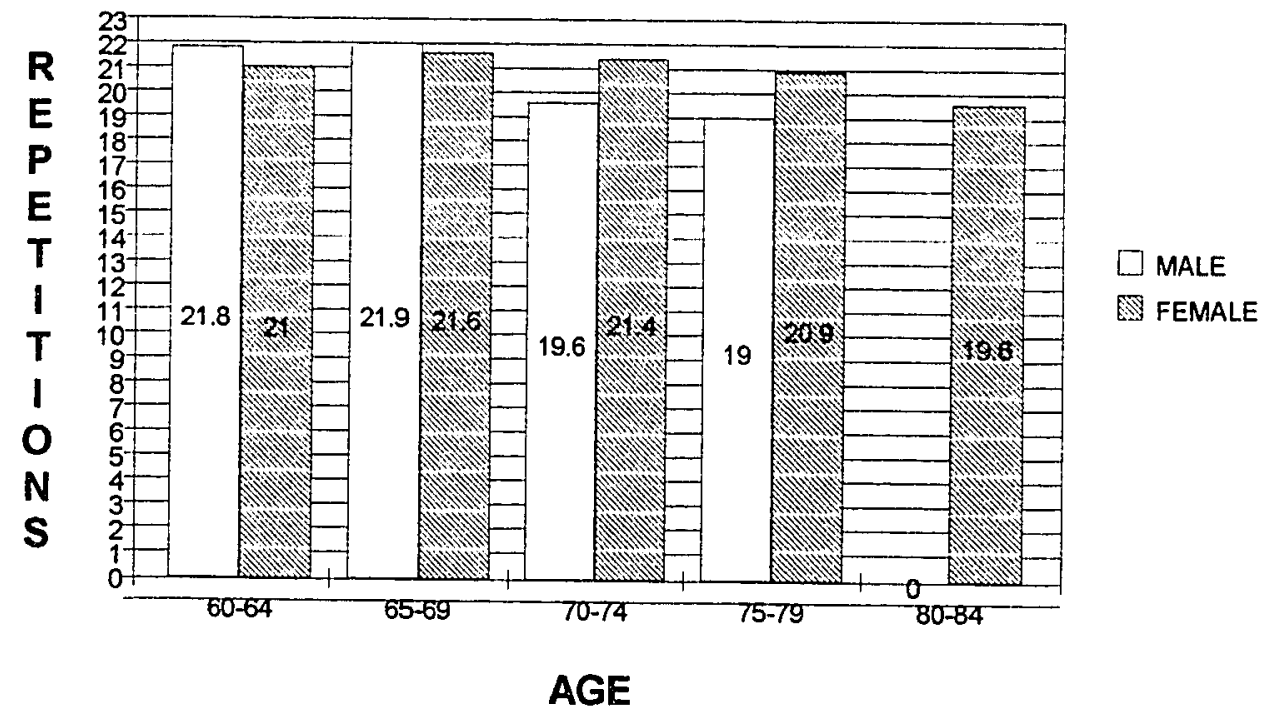

\section{Graph 4. Strength Factor Performance.}

\section{Endurance}

The half-mile walk, reported in minutes, provided a functional assessment of the walking ability in older adults. As reported in Graph 5, the data demonstrated that there was an increase in the mean time as one gets older. The difference across the means only varied $20-30$ seconds. For the male subjects, as shown in Table 1, there was an increase in mean time in the $65-69$ age interval as compared to the 60-64 and and 70-74 age intervals due to one score at the high end of 11.1 minutes. The 
standard deviations (range $=1.4-1.9$ ) were relatively consistent across the age intervals.

The female subjects, as shown in Graph 5 , showed a steady increase in time for the half mile walk over the age intervals. The standard deviations (range $=1.0-1.5$ ) were relatively consistent across the age intervals. The increase in time over the age intervals may be due to decreased mobility, decreased activity level, and a decrease in muscle mass and a decrease in VO2 max as one grows older as seen in the wide range of scores in cach age interval for male and female subjects.

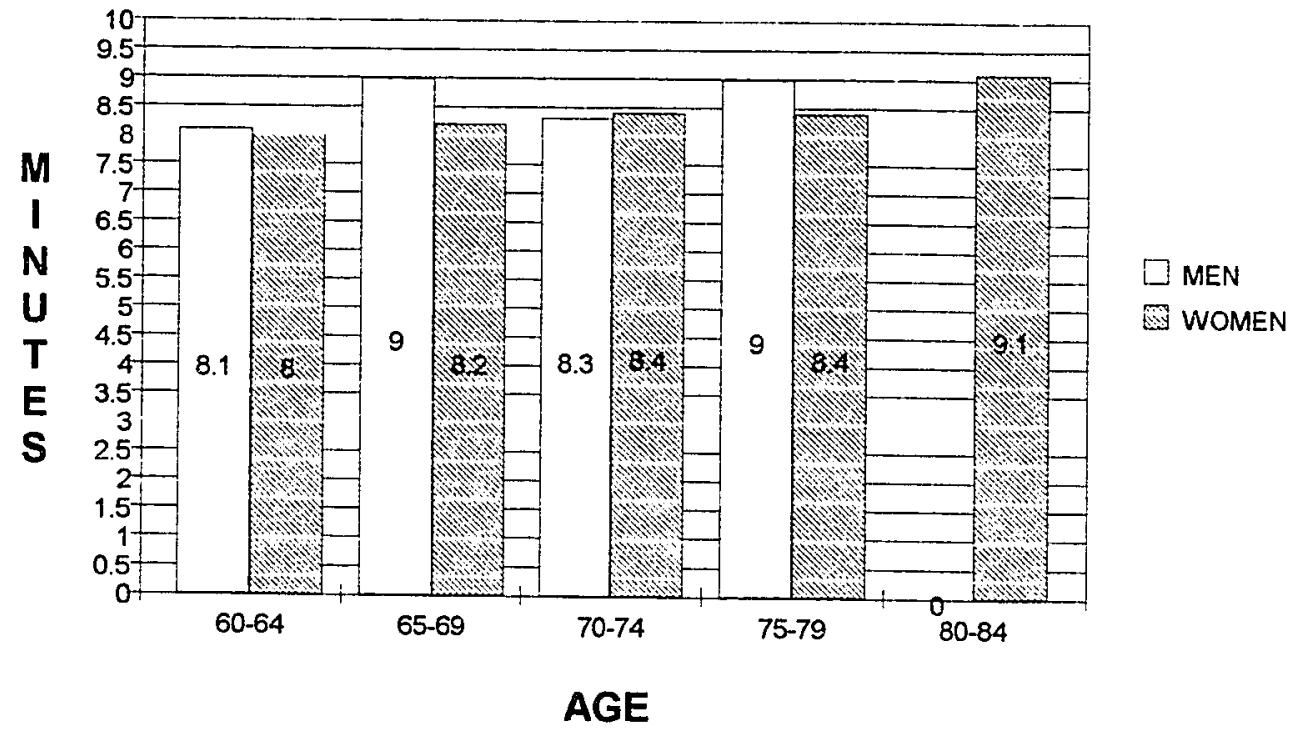

Graph 5. Endurance Factor Performance. 


\section{Reference Profile}

The purpose of this project was to provide a reference profile, including percentile tables, for fitness instructors of older adults in the Santia Clara Counity area. The percentile tables, Table 2 and Table 3 , are defined by the data from this study and demonstrate values in which the fitness instructor can compare the scores of the person's performance on the AAHPERD Functional Fitness Test Battery.

\section{Summary}

The purpose of this project was to provide a reference profile for fitness instructors of older adults in the Santa Clara County area. The instructors can use the AAHPERD Functional Test Battery to test their population in a practical manner and then compare their scores with the norms provided from this project. The instructor can then address the older adult's fitness strengths and weaknesses and provide ameliorative exercises. The project reference profile is a guide only, to provide the fitness instructor with a starting reference point for an age interval. This reference profile indicates that there is a decrease in flexibility, an increase in time for the agility/dynamic test, a decrease in coordination, a decrease in strength, and an increase in time for the half mile walk as one increases with age. 


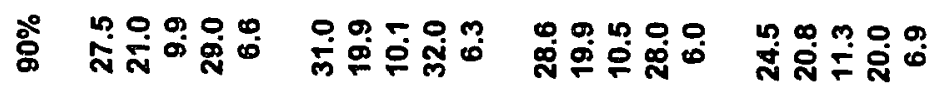

远

ஓं

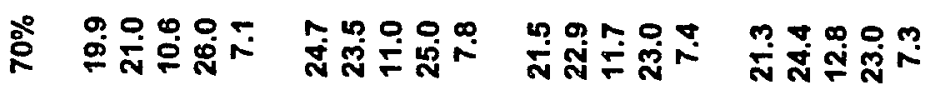

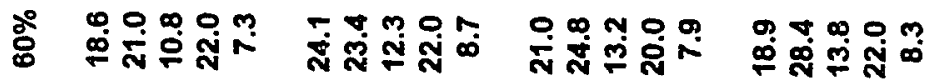

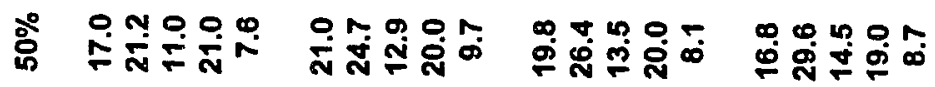

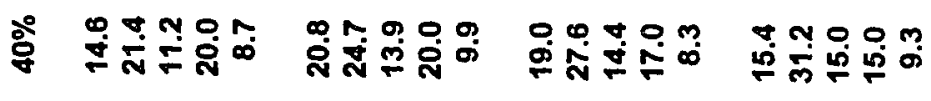

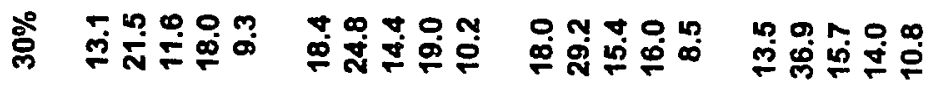

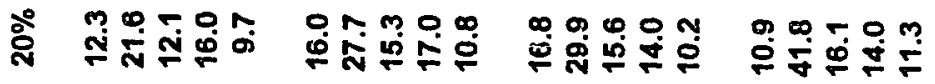

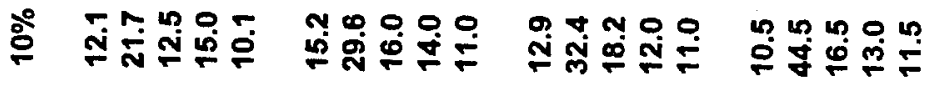

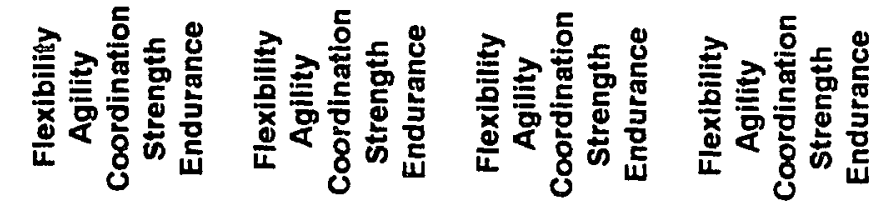

B

递

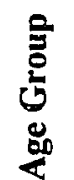

0
$\substack{9 \\ 0}$
0

î́

م)

نั 


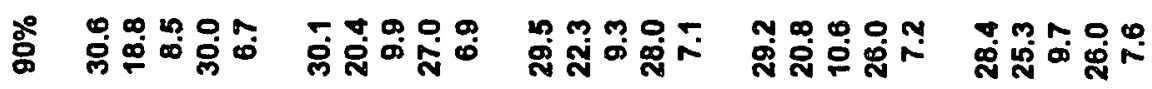

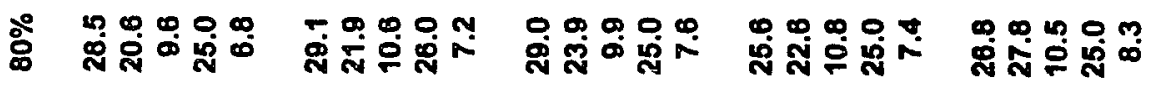

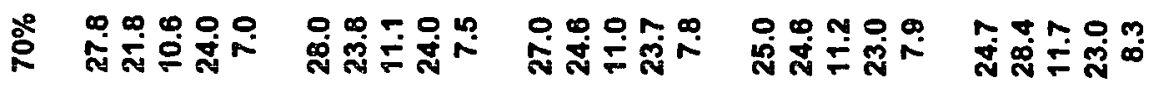

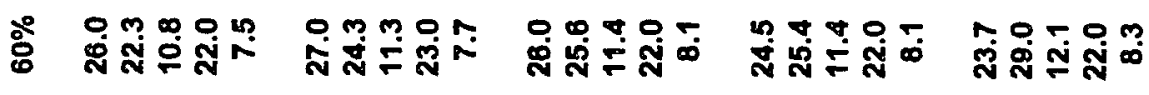

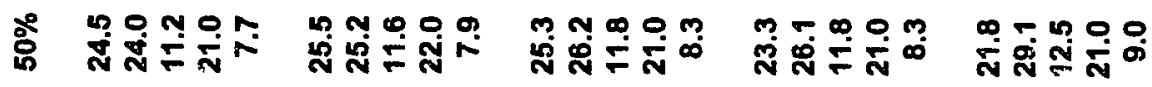
衷

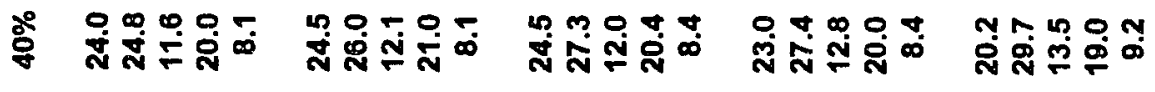

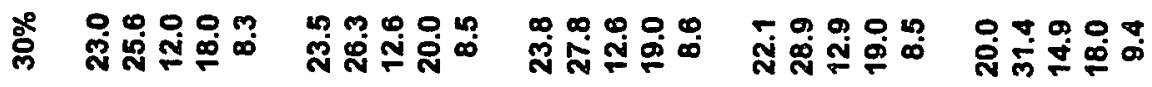

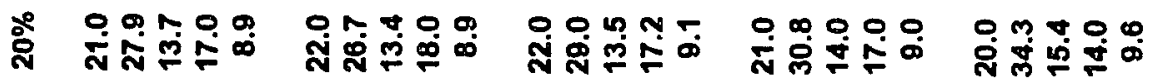

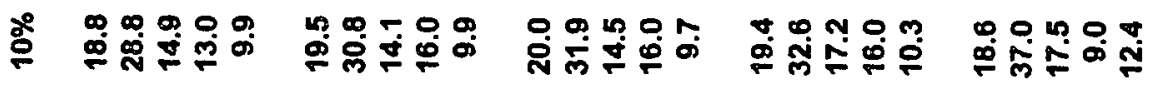

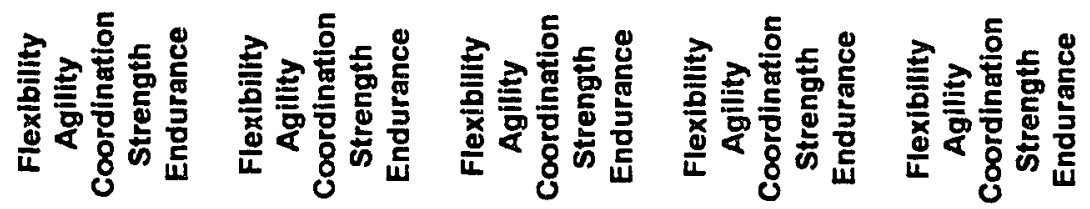

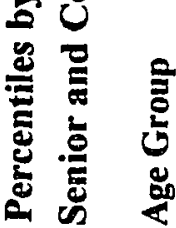

$\Phi$

8
9
8
8

$\frac{⿱}{d}$

مึ

\$

ल) 


\section{CHAPTER V}

\section{DISCUSSION}

The purpose of this project was to assess the functional fitness level of older adults over age 60 years in select Senior and Community Centers in the Santa Clara County Area. Utilizing the AAHPERD Functional Fitness Test Battery, a reference profile of the functional fitness level of this population was developed to encourage its use by fitness educators of older adults in customizing their exercise programs to each individual. This chapter will address the utilization of the AAHPERD Test Battery and the development of the Reference Profile for this project. Dissemination of the Reference Profile data and recruitment strategies will also be discussed, followed by recommendations for future studies.

\section{AAHPERD Functional Fitness Test Battery Results and Discussion}

There were select items in the AAHPERD Functional Fitness Test Battery that had data with higher standard deviations than others. One obvious example was the strength test. The test purports to measure upper body strength as demonstrated through the number of times the subject could do bicep curls in thirty seconds. The female subjects used a $4 \mathrm{lb}$. dumbbell while the males used an $8 \mathrm{lb}$. dumbbell. Some female subjects mentioned that the $4 \mathrm{lb}$. dumbbell was too heavy for them. Also, some 
of the female and male subjects performed the bicep curl slowly, focusing on accuracy, while others performed it faster without regard to precise performance. The test instructions simply stated for the subject to perform the bicep curl by full extension down with the arm and raise to touch the technician's hand, which would be placed on the subject's bicep. Thus, there was a wider range of scores for the male and female subjects across the age intervals due to the varying speed of bicep curl performance. This caused the standard deviation for the males and females to range from 5.3-6.0 and $4.2-6.2$ repetitions, respectively. The test instructions did not state how fast the subject should perform the arm curl (for example, slow and accurate vs. fast and accurate). The AAHPERD Test Battery instructions for this item should be changed to reflect the speed in which to perform the arm curl.

The results of this project, particularly female subject data, support the research that documents the decline of select physiological body functions as one get older. Flexibility tends to decline with age and this decline is related to changes in the connective tissue of the muscles and ligaments (Raab, 1988). There is alteration to the fibrous proteins, elastin, and collagen of the cartilage, ligaments, and tendons of the joints, especially in the weight-bearing joints such as the knee and hip. These changes result in increased rigidity or stiffness in the joint (Adrian, Flatten, \& Lindsey, 1989). 
Flexibility can also be associated to bone loss as it presents a significant problem to women over the age of 60 and to men over the age of 80 . Women lose approximately one percent/year after age 35 while men lose about 0.4 percent/year in bone mass. With decreased flexibility and increased bone loss, there is a tendency for more falls and broken bones in the older adult (Smith \& Gilligan, 1989). But physical activity can play an important role in increasing flexibility and maintaining bone or reversing bone loss.

Coordination also seems to decrease with age as there apppears to be an increase in reaction time. As adults get older, it is important for them to maintain their mobility and, as shown from the majority of scores, one loses the ability to move efficiently as one grows older. Impulses from the nerve to the muscle cell membrane and, therefore, muscle contraction in response to stimuli are slowed (Spirudoso, 1989). Nerve conduction velocity declines from $10-30 \%$ from 30 to 80 years of age and there is a $37 \%$ decline in the number of spinal cord axons. The above decreases and the changes in the connective tissue may explain the increase in simple and complex reaction time (McArdle, Katch, \& Katch, 1986). There appears to be an increase in performance time in the coordination test and thus a decline in neuromuscular efficiency as one grows older. 
There are also age-related decreases in muscle mass, power, strength, and endurance (Steen, 1988). Skeletal muscle consists of both slow and fast twitch fibers. There are changes in the muscle structure including a decrease in size and number of Type II muscle (fast twitch) as one ages. It was expected that the female subjects would have more of a decline in strength due to age, but this was not the factor. It may be due to the consistent activities of daily living involving strength which kept their scores similar across the age intervals. The male subjects showed a decline in strength as expected but not until the $70-74$ age interval.

According to research, there is also a decline in cardiovascular functioning as one ages. This decline results from changes in both the heart and vascular system. The blood vessels may show a loss in elasticity and an increase in stiffness, causing resistance to blood flow. Blood pressure also may rise with increasing age (Adrian et al., 1989). The heart muscle is weaker and maximum heart rate lower (6-8 beats/decade) (Shephard, 1985). The increase in time in the Walk test over the age intervals may be due to the declining cardiovascular system as one grows older. Thus, the results of this project support the research that, as one ages, there is a decline in select physiological functions of the human body. 


\section{Reference Profile Data Results and Discussion}

With increasing age, the males appeared to decline in function according to the data reported from this project. One must use caution when drawing conclusions from the male data since there were only 50 subjects involved and each age interval had between 4 and 18 subjects. Werder and Kalakian (1985) cautioned that developers are often 'forced' to use optimum sample sizes when compiling norms for special populations. "When the number in a normative group is small from one age group to the next for any given test item, the evaluator often observes a phenomenon called 'spiking norms'"' (p. 36). The project data for the Endurance (half-mile walk) test item by male is an excellent example of 'spiking norms' due to small and varied subject sizes. It is hoped that the national norms being compiled by Dr. Wayne Osness will have optimal sample sizes for their age and gender categories.

The female subjects appeared to maintain their fitness level from age 60 to 75 year as shown in the graphs in Chapter 4. There seemed to be a consistent trend in all of the test items for the three age intervals. From 75 years on, there appeared to be a more significant decline in all of the test items according to the data gathered from this project. 


\section{Dissemination of Reference Profile Data}

The data from this study was sent to Dr. Wayne Osness, University of Kansas, Chairperson, AAHPERD Fitness Task Force for the Functional Fitness Test Battery. He is compiling data from across the United States to create preliminary national norms of the AAHPERD Functional Fitness Test Battery for Adults over Age 60. Locally, this study resulted in a reference profile to be disseminated to fitness instructors of older adults. This reference profile indicates that there is a slight decrease in flexibility in select gender and age intervals, an increase in time for the agility/dynamic test, a decrease in coordination, a decrease in strength, and an increase in time for the half mile walk as one increases with age. This reference profile will be made available to all Senior and Community Centers in Santa Clara County. It will also be published in the official newsletter of the professional organization called 'Fitness Educators of Older Adults', located in Sunnyvale, California.

\section{Conclusions}

As stated in the previous chapter, this reference profile provided information as to the fitness level of adults over age 60 at selected sites in the Santa Clara County area. The results are consistent with findings that as one ages, there is a decrease in select physiological functions of the human body. Exercise can play a role in 
maintaining one's fitness level longer. As stated by Smith and Zook (1986), it is the quality of life that counts and not the quantity of life.

The researcher found that most sites that were contacted about this project were cooperative but some did not choose to participate in this study. The researcher found it frustrating that these Senior Coordinators, who are supposed to be informed on all aspects of the older adult, are not concerned about the fitness level of their clients. Some older adults and older adult instructors who were contacted by the researcher also did not wish to participate in the fitness assessment, even though the benefits of such a project and the minimal time involved for project participation were stated. More males were unwilling to participate than the females. The Senior and Community Centers seem to have a larger female older adult population and males were difficult to recruit. Thus, that is why there were such low numbers (50 males) to the number of females (235) who participated in this project.

Another example of a low tumout of older adult subjects was at the Evergreen Community Center. The researcher advertised in the San Jose Mercury News, in the Sports Venture Section, for four weeks before the testing date. It was also advertised in two local papers, the Evergreen Times and The Villager. The Evergreen Community Center advertised the date and time for the testing in their brochure and 
only 13 people showed up to participate in the AAHPERD Functional Fitness Test Battery over a two hour period. This was consistent with the other testing sites too. The researcher also spoke at local nutrition sites and every center put out fliers and posters to advertise the testing date and time. The researcher then went to older adult instructors and solicited volunteers from different exercise classes. Thus, that is why there was a low turnout of participants at each testing site.

\section{Limitations}

The limitations of this project were the following:

1. Sample size may not have been an adequate representation of the population of the male and female population in Santa Clara County.

2. Subjects were limited to a select geographical area and selected Senior and Community Centers who volunteered to participate.

\section{$\underline{\text { Recruitment Strategies }}$}

The following suggestions are being made for better recruitment of adults over age 60:

1. Utilizing this reference profile, demonstrate to the Senior Coordinators how important physical activity is for adults over age 60 , citing there will be a significant increase in the older adult population in the next 20 years. 
2. Stress the "wellness" issue with the Senior Coordinators.

3. Spend more time recruiting Senior and Community Centers by physically visiting each site and talking with the Senior Coordinator at each site.

4. Speak to the fitness instructor(s) who teach at each site to obtain their cooperation since this way worked the best for the researcher in this project.

5. Follow-up each visit with a letter and a phone call to ask for the Center's cooperation and participation.

6. Visit classes and activities at each site to solicit volunteers.

7. Apply for grant money for advertising and publicity.

8. Get affiliated with hospitals and Community Colleges to recruit volunteers.

8. Give some kind of financial incentive for older adults to participate.

The benefits of physical activity programming for the older adult are clear.

Assessment of physical capabilities and the establishment of goals for an individual are necessary in order to design appropriate physical activity programs for older adults. The first priority for exercise programs is to achieve and maintain fitness sufficient to perform the activities of daily living independently. Fitness educators of older adults need to know their students' strengths and weaknesses and plan ameliorative exercises. 
This reference profile provides that information to fitness instructors who need to construct a quality exercise program to meet the individual needs of their students. 


\section{REFERENCES}

AAHPERD. (1985). Testing for impaired, disabled and handicapped individuals.

Reston, VA: American Alliance for Health, Physical Education, Recreation, and Dance (AAHPERD).

AAHPERD Fitness Task Force. (1988). Working Draft Manual. Unpublished manuscript.

AAHPERD. (1990). Functional fitness test battery for adults over age 60 test manual. Reston, VA: AAHPERD.

Adrian, M. (1989). Movement fitness: A biomechanical approach to fitness for the older person. CAHPERD Journal and Times, $\underline{5}$ (4), 23-24.

Adrian, M., Flatten, F., \& Lindsey, R. (1989). Biomechanical and related sciences for the older adult. In D. Leslie (Ed.), Mature Stuff (pp. 81-92). Reston, VA: AAHPERD.

American College of Sports Medicine. (1986). Guidelines for exercise testing and prescription. Philadelphia: Lea \& Febiger.

Blair, S.N., Brill, R.A., Kohl, H.W. (1989). Physical activity pattern in older individuals. In W. Spirduso, \& H.M. Eckert (Eds.), Physical activity and aging (pp. 120-139). Champaign, ILL.: Human Kinetics. 
Brody, E., Kleban, M., \& Oriol, W., (1985). Mental and physical health practice of older people. New York: Springer Publishing Company.

Clark, B. (1989). Tests for fitness in older adults. JOHPERD, 16 (3), 66-71.

Clark, H. H. (Ed.). (1977). Exercise and aging. Physical fitness research digest, Series 7 (2). Washington, D. C.: President's council on physical fitness and sports.

Compton, D., Eisenman, P., \& Henderson, H. (1989). Exercise and fitness for persons with disabilities. Sports Medicine, $\underline{7}, 150-162$.

Corbin, D., \& Metal-Corbin, J. (1990). Reach for it. Dubuque, Iowa: Eddie Bowers. Donahue, R.P., Abbott, R.D., Reed, D.M., \& Yano, K. (1988). Physical activity and coronary heart disease in middle-aged and elderly men: The Honolulu heart program. American Journal of Public Health, 78, 683-685.

Eischstaedt, C., \& Kalakian, L. (1993). Developmental/adapted physical education. New York: Macmillan.

Fiatarone, M.A. \& Evans, W.J. (1990). Topics in Geriatric Rehabilitation, 5 (2), 63-77.

Flieger, K. (1988). Why do we age? FDA Consumer. In H. Cox (Ed.), Aging (8th ed.) (pp. 6-9). Guilford, CT: Dushkin Publishing Company. 
Haskell, W. (1989). Exercise: Measurement, dose-response relations and compliance. In J. Skinner, C. Corbin, D. Landers, P. Martin, \& C. Wells (Eds.), Future directions in exercise and sport science research (pp. 57-70). Champaign, IL: Human Kinetics.

Isaacs, L. (1989). The role of an active lifestyle in maintaining movement proficiency. CAHPERD Journal and Times, $\underline{51}$ (4), 7-8.

Kaplan, G.H., Seeman, T.E., Cohen, R.D., Knudsen, L.P., \& Guralnik, J. (1987). Mortality among the elderly in the Alameda County Study: Behavioral and demographic risk factors. American Journal of Public Health, 77, 307-312.

Kasch, F.W., Wallace, J.P., Van Camp, S.P., \& Verity, L.W. (1988). A longitudinal study of cardiovascular stability in active men aged $45-65$ years. Physician and Sports Medicine, 16, 117-123.

Kenney, R. (1982). Physiology of Aging: A synopsis. Chicago: Year Book Medical Publishers, Inc.

Kisner, C., \& Colby, L.A. (1990). Therapeutic exercise foundations and techniques (2nd ed.). Philadelphia: F.A. Davis.

Koss, R. S. (1989). Characteristics of older adults. In D. Leslie (Ed.), Mature stuff. Reston, VA: AAHPERD. 
La Porte, R.E., Montoye, H.J., \& Caspersen, C.J. (1985). Assessment of activity in epidemiologic research: Problems and prospects. Public Health Reports, $\underline{100}$, $131-145$.

Lasko, P. (1988). Assessment of adult disabilities at the post-secondary level. Presented at Physical Activity Conference for the Exceptional Individual, Seventeenth National Conference, October, 1988.

McArdle, W. D., Katch, F.I., \& Katch, V. L. (1986). Exercise physiology. Philadelphia: Lea \& Febiger.

McLean, C. (1992). The graying of America. In H. Cox (Ed.), Aging (8th ed.) (pp. 15-21). Guilford, CT: Dushkin Publishing Company.

Morris, J.N., Everitt, M.G., Pollard, R., Chase, S.P.W., \& Semiing, A.M. (1980). Vigorous exercise in leisure time: Protection againt coronary heart disease. Lancet, II, 1207-1210

National Institute on Aging. (1985, October). Seventh Report to council on program of the aging. U.S. Department of Health and Human Services.

Osness, W. (1989). The AAHPERD task force. JOHPERD, 60, (3) 64-65.

Osness, W. (1992). Personal communication, November 12, 1992. 
Paffenberger, R.S., Hyde, R.T., Wing, A.L. (1986). Physical activity, all cause mortality and longevity of college alumni. New England Journal of Medicine, 314, 605-613.

Petray, C., Blazer, S., Lavay, P., \& Leeds, M. (1989). Designing the fitness testing

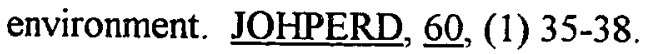

Prentice, W.E. \& Bucher, C.A. (1988). Fitness for college and life. St. Louis: Times Mirror/Mosby College Publishing.

Raab, D. (1988). Light resistance and stretching exercises in elderly women: Effect upon flexibility. Archives of Physical Medicine and Rehabilitation, $\underline{69}$, 268-272

Reid, J.R. \& Thompson, (1985). Exercise presciption for fitness. Englewood Cliffs, N.J.: Prentice-Hall, Inc.

Ross, J., Pate, R., Delpy, L., Gold, R., and Svilar, M. (1987). New health related fitness norms. $\underline{\text { JOHPERD, }} \underline{\mathbf{5 8}},(9), 66-69$.

Schmidt, R. (1988). Motor control and learning. Champaign, IL: Human Kinetics

Shepard, R. (1978). Physical Activity and Aging. Chicago: Year Book Medical Publishers, Inc. 
Shepard, R. (1985). Physiology of aging and adapted physical activity. In M.E. Berridge \& G.P. Ward (Eds.). International perspectives on adapted physical activity (pp. 235-242). Champaign, IL: Human Kinetics.

Sienna, P. (1989). One rep max. Indianapolis, Ind: Benchmark Press, Inc.

Skinner, J.S. (1987). Importance of aging for exercise testing and prescription. In J. Skinner (Ed). Exercise testing and exercise prescription for special cases. Philadelphia: Lea \& Febiger.

Smith, E.L., \& Zook, S.K., (1986). The aging process: Benefits of physical activity. JOHPERD 57 (1), 32-34.

Smith, E. L., \& Gilligan, C. (1989). Biological aging and the benefits of physical activity. In D. Leslie (Ed.), Mature stuff (pp. 45-60). Reston: VA:

\section{AAHPERD.}

Spirduso, W. (1985). Age as a limiting factor in human neuromuscular performance. In H. Clarke \& H. Eckerte (Eds.). The academy papers: Limits of human performance (pp. 57-69). Champaign, IIl: Human Kinetics Publishers, Inc.

Spirduso, W. (1989). Physical activity and aging. Champaign, IL: Human Kinetics.

Steen, B. (1988). Body composition in aging. Nutrition Reviews, $\underline{46}, 41-51$. 
Werder, J. K. \& Kalakian, L. H. (1985). Assessment in adapted physical education. Minneapolis: Burgess Publishing. 


\section{APPENDIX A \\ INFORMED CONSENT}

You are invited to participate in a project which will assess your current fitness level and which will provide a reference profile for other exercise leaders who teach older adult exercise classes. You will receive an individualized fitness profile with your results. If you decide to participate, you will perform various fitness activities which will assess your current fitness level. The test will consist of a flexibility testmodified sit and reach test; agility/dynamic balance test- chair agility test; coordination test- "soda pop" coordination test;; strength/endurance test- arm curl test; and an endurance test- half mile walk. These tests will be explained in detail before you decide to participate.

There may be a risk of falling during the 880 yard walk and chair agility test. Any muscle soreness experienced is expected to subside after several days.

Your decision whether or not to participate will not prejudice your future relations with San Jose State University, or your Senior or Community Center. If you initials 
decide to participate, you are free to withdraw your consent and to discontinue participation at any time without prejudice. Any information that is obtained in connection with this study and that can identified only with your permission or as required by law.

At your request, you will be given a copy of this form. The investigator will answer any questions. Ruth Haynes can be reached at (408) 378-1713, Dr. Nancy Megginson, Department of Human Performance, (408) 924-3014 or Dr. James Bryant, Chairperson, Department of Human Performance, (408) 924-3010. Questions or complaints about this project, subject's rights, or project-related injury may presented to Dr. Serena Stanford, Associate Academic Vice President for Graduate Studies and Research, at (408) 924-2480. Your signature indicated that you have decided to participate having read the information given above.

Signature

Signature of Witness

Signature of Researcher

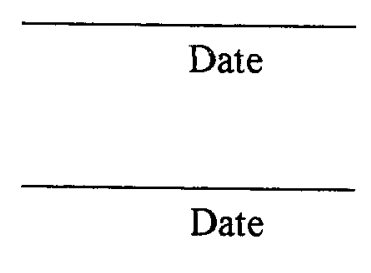

Date 


\section{APPENDIX B \\ PHYSICAL ACTIVITY READINESS QUESTIONNAIRE}

For most people, physical activity should not pose any problems or hazard.

PAR-Q has been designed to identify the small number of adults for whom physical activity might be inappropriate or those who would have medical advice concerning the type of activity most suitable for them.

$\mathrm{Y} \quad \mathrm{N}$ 1. Has your doctor ever said you have heart trouble?

$\mathrm{Y} \quad \mathrm{N} \quad 2$. Do you frequently suffer from pains in your chest?

$\mathrm{Y} \quad \mathrm{N} \quad$ 3. Do you often feel faint or have spells of severe dizziness?

Y N 4. Has a doctor ever told you that you have bone or joint problems such as arthritis that has been aggravated by exercise, or might be made worse with exercise?

$\mathrm{Y} \quad \mathrm{N}$ 5. Is there a good physical reason not mentioned here why you should not follow an activity program even if you wanted to?

$\mathrm{Y} \quad \mathrm{N}$ 6. Are you over age 65 and not accustomed to vigorous exercise?

$\mathrm{Y} \quad \mathrm{N}$ 7. Do you participate in an aerobic activity at least three times a week?

$\mathrm{Y} \quad \mathrm{N} \quad$ 8. Do you strength train at least two times a week?

If you answer yes to questions 1-6, vigorous exercise or exercise testing should be 
postponed. Consult your personal physician if you wish to participate in this functional fitness test battery. Please pick up a medical release form from the test administrator to be filled out by your personal physician and returned to the test administrator. 


\section{APPENDIX C}

\section{AAHPERD FUNCTIONAL FITNESS TEST BATTERY}

Parameter: Flexibility

Test Item: Trunk/Leg Modified Sit and Reach

Equipment: Yardstick, masking tape

Procedure:

Equipment Set-up: Draw a line approximately twenty inches long on the floor, or you may use masking tape for this line. Tape the yardstick to the floor perpendicular to the line, with the twenty-five inch mark directly over the line. If masking tape is used for the line, the twenty-five inch mark should be right on the edge of the tape. Next, draw two marks on the line, each six inches away from the center of the yardstick (See Figure 1).

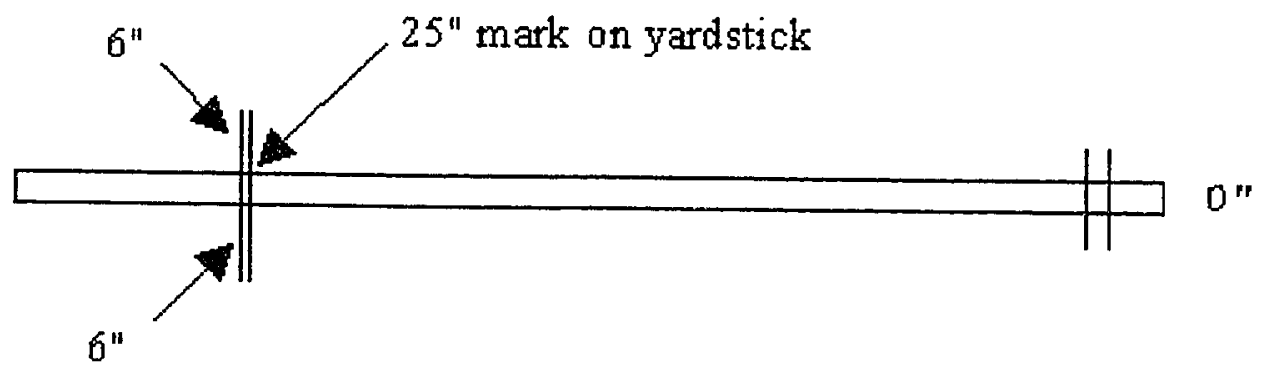

\section{Figure 1. Equipment Set-up for the Trunk/Leg Flexibility Test.}

Directions: The subject should remove the shoes for this test and sit on the floor with legs extended, feet twelve inches apart, toes pointing straight up, and heels right up against the line (at the twenty-five inch mark, and each heel centered at the six-inch marks on the line). The yardstick should be between the legs, with the zero point toward the subject. The hands are placed one directly on top of the other. The subject may then slowly reach forward sliding the hands along the yardstick as far as possible, and hold the final position for at least two seconds. The technician 
administering the test should place one hand on top of one knee only to insure that the subject's knee is not raised during the test.

Scoring: Record the final number of inches reached to the nearest one-half inch.

Trials: Two practice trials followed by two test trials are given. Only the score for the two test trials are recorded.

Approximate Range of Scores: Ten to thirty inches

Special Considerations: Be sure that the subjects are properly warmed-up prior to this test. Specific exercises related to this task should be conducted prior to this test. Help all subjects into the sitting position and subsequently when getting up from the floor. The forward reach should be a gradual movement along the top of the yardstick, the tip of the middle fingers must remain even during the entire reaching action, and the final position must be held for at least two seconds. Be sure that the toes are straight up and that the legs are kept as straight as possible. If the feet start tuming outward and the knees start to come up during the reaching action, ask the subject to maintain the correct position. 
Parameter: Agility/Dynamic Balance

Test Item: Chair agility Test

Equipment: Chair with arms (average seat height 16"), masking tape, measuring tape, two cones, and stop watch

Procedure:

Equipment Set-up: The initial placement of the chair should be marked with the legs taped to the floor, if possible, because the chair tends to move during the test. Measuring from the spot on the floor $(x)$ in front of the chair where the feet will be placed, the cones are set up with their farthest edge located six feet to the side and five feet behind the initial measuring spot (x). One cone is set up at either corner behind the chair (See Figure 2). The area should be well lit, the floor even and non slippery.

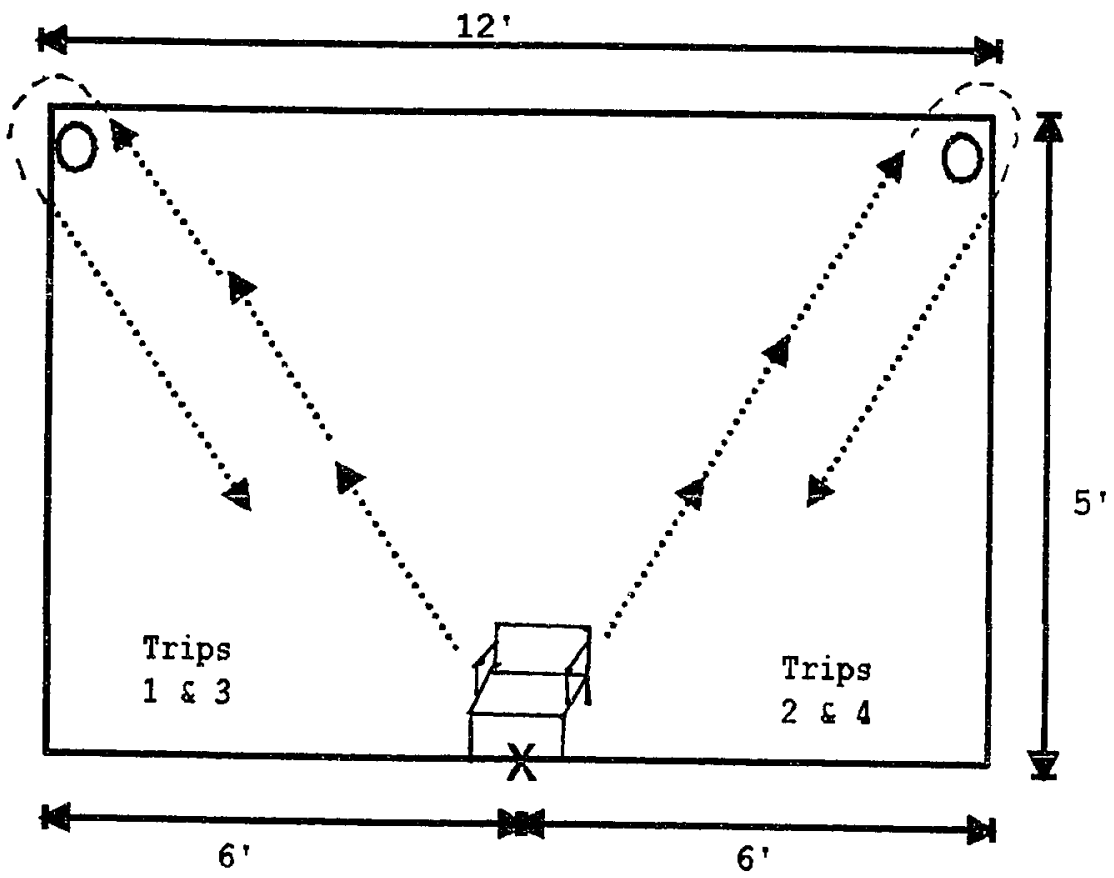

Figure 2. Chair Set-up for the Agility/Dynamic Balance Test. 
Test Administration: The person begins fully seated in the chair with the heels on the ground. On the signal, "Ready, Go!", the person gets up from the chair, moves to their right going to the inside and around the back of the cone to their right (counterclockwise), returns directly to the chair and sits down. Without hesitating, the person gets and immediately moves to the left again, going to the inside and around the back of the cone to their left (clockwise), returns directly to the chair and sits down completing one circuit. The person gets up immediately and repeats a second circuit exactly as the first. One trial consists of two complete circuits (going around the cones four times: right, left, right, left).

During the test, after circling the cones, the person must sit down fully in the chair. This means having the person lift the feet $1 / 2$ inch from the floor before getting up. The person must use their hands to help get in and out of the chair. The person should go as fast as one feels comfortable without losing one's balance or falling.

Instructions to the participant: Explain the test procedures, then walk the person through the course and make sure they circle the cones correctly and lift their feet each time they sit down.

After sufficient practice, the person should be given the following instructions: "Walk as fast as possible without feeling you will lose your balance or fall. One trial consists of circling the cones four times. The first time, go to your right and then to your lift, right and left. Go around the cone from the inside to the outside, come back and sit down after circling each cone. Sit down fully and lift your feet off the floor each time. Use your hands to help you get in and our of the chair without falling. If you feel dizzy, light headed, or any pain, stop immediately and tell me."

Administrative Cues: Give directions, supervise practice, and start each trial with "Ready, Go!" Start the stopwatch when the person begins to move, stop the watch when the person sits down the fourth time.

During the test, give verbal directions (example: right, left, around, sit down, etc.) so the person does not have to stop or hesitate because they are confused. Make sure the person lifts their feet each time they sit down.

If the person moves the chair, the technician should readjust it to the original position during the trial. 
Scoring: Record the times for each trial to the nearest tenth of a second.

Trials: A practice "walk through" is administered until the person demonstrates they they understand the test. Three trials are administered with a thirty second rest provided after trial.

Approximate Range of Scores: Fifteen to thirty-five seconds. 
Parameter: Coordination

Test Item: "Soda Pop" Coordination Test

Equipment: Three unopened (full) cans of soda pop, a stopwatch, 3/4 inch masking tape, a table, and a chair.

Procedure:

Equipment Set-Up: Using the 3/4 inch masking tape, place a 30" strip of tape on the table, about five inches from the edge of the table. Draw six marks exactly five inches away from each other along the line of the tape, starting at $21^{\prime 2}$ inches from either edge of the tape. Now place six strips of tape, each three inches long, centered exactly on top of each of the six marks previously drawn. For the purposes of this test, each little 'square' formed by the crossing of the long strip of tape and the three-inch strip of tape is assigned a number starting with 1 for the first square on the right to 6 for the last square on the left ( See Figures 3 ).

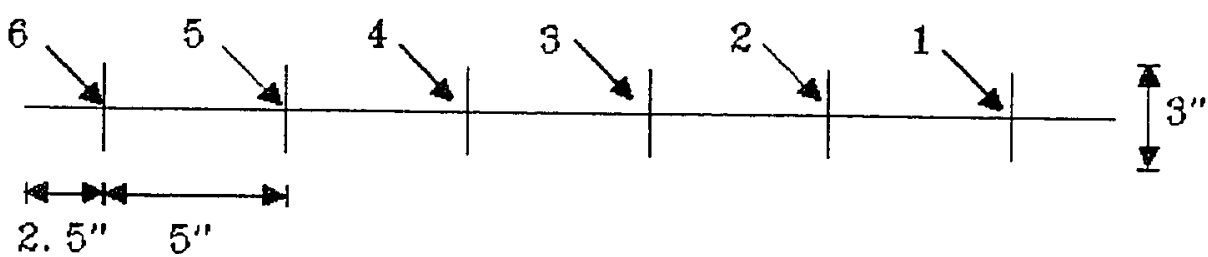

Figure 3. Masking Tape Placement for the "Soda Pop" Coordination Test.

Directions: To administer the test, have the subject sit comfortably in front of the table, the body centered with the diagram on the table. The preferred hand is used for this test. If the right hand is used, place the three cans of soda pop on the table in the following manner: can one is centered on square 1 (farthest to the right), can two on square 3 , and can three on square 5 . To start the test, the right hand with the thumb up is placed on can one with the elbow joint at about 100-120 degrees. When the technician gives the signal, the stopwatch is started and the subject proceeds to the cans of soda pop upside down, placing can one over square 2, followed by can two over square 4 , and then can three over square 6 . Immediately, the subject returns all three cans, starting with can one, can two, and then can three,--turning them right side 
up to their original placement. On this "return trip", the cans are grasped with the hand in a thumb down position. This entire procedure is done twice, without stopping, and is counted as one trial. The watch is stopped when the last can of soda pop is returned to its original position, following the second trip back. The preferred hand (in this case, the right hand) is used throughout the entire task (a graphic illustration of this test is provided in Figure 4). The object of the test is to perform the task as fast as possible, making sure that the cans are always placed over the squares. If a can misses a square at any time during the test, the trial must be repeated from the start. A miss indicates that a can did not completely cover the entire square formed by the crossing of the two strips of tape (See Figure 5).

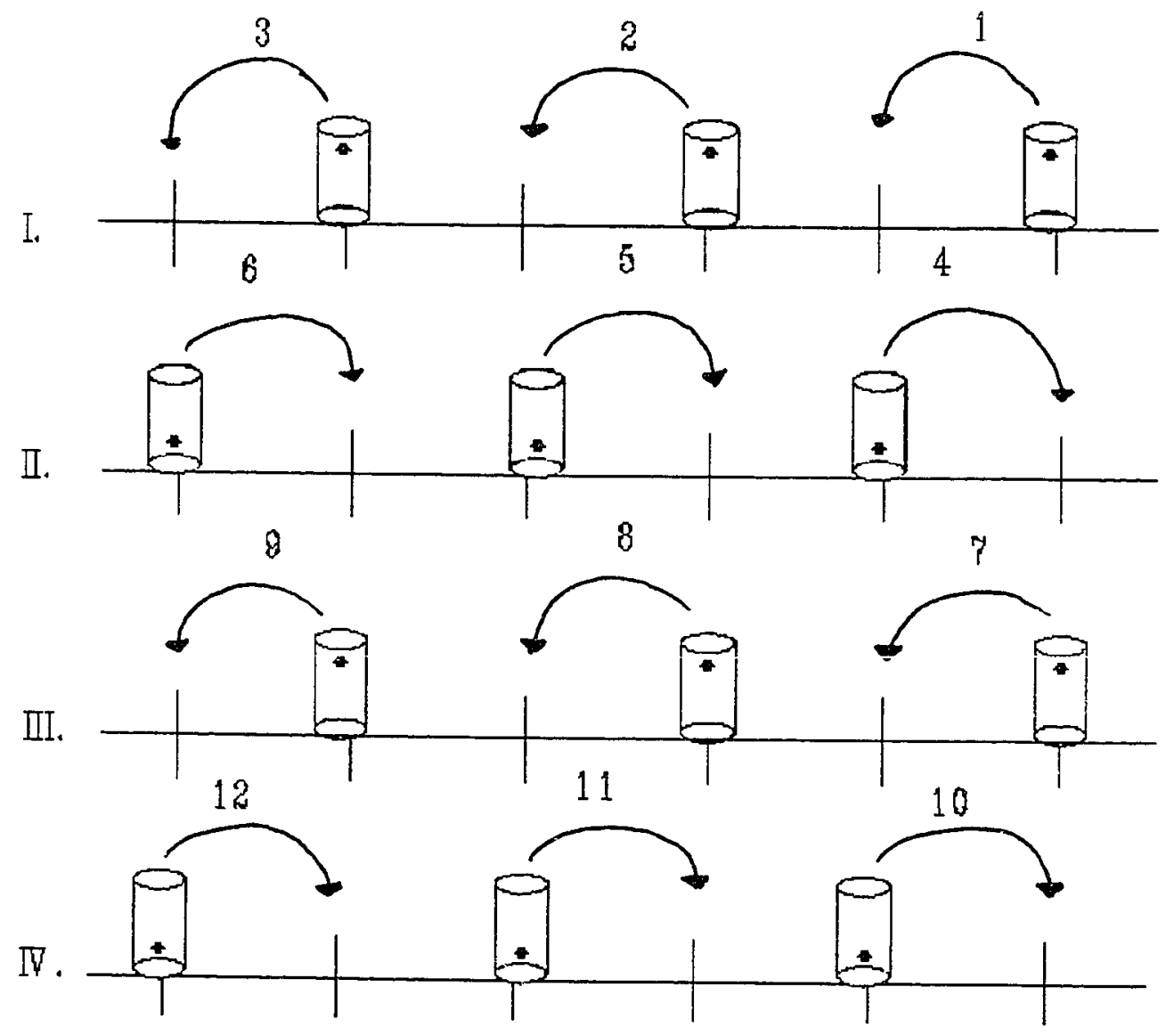

Figure 4. Coordination Test Movement Sequence. 


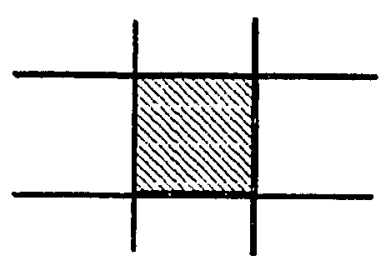

\section{Figure 5. Shaded Area Coverage for the "Soda Pop" Coordination Test.}

If the participant chooses to use the left hand, the same procedures are used, except that the cans are placed starting from the left; with can one over square 6 , can two over square 4 , and can three over square 2 . The procedure is initiated by turning can one upside down onto square 5 , can two onto square 3 , and so one.

Scoring: Record he time of each test trial to the nearest tenth of a second.

Trials: Two practice trials followed by two test trials are given. Only the scores for the two test trials are recorded.

Approximate Range: Eight to twenty-five seconds.

Special Considerations: During the entire procedure, the cans must completely cover the squares formed by the crossing of the two tapes. If the person has a mistrial (misses a square), repeat the test until two successful trials are accomplished. 
Parameter: Strength/Endurance

Test Item: Arm Curl Test

Equipment: Two sets of dumbbells, 4 pounds and pounds, (or as an alternative; two-quart plastic bottle with handle, one-gallon bottle with hand, sand or other similar material:, stopwatch, normal straightback chair without arms

Procedure:

Equipment Set-Up: If dumbbells are not available, the two-quart empty plastic bottle should be filled with sand, water, or other material to four pounds of total weight nd the cover tightened. The one-gallon empty plastic bottle should be filled in the same way to eight pounds and the cover tightened. A straight back chair with no arms is placed in the area with no obstructions.

Test Administration: The subject is asked to sit in the chair with their back straight and against the back of the chair as much as possible. The eyes should be looking straight and the feet flat on the floor in a comfortable position. The non dominant hand should be resting in the lap with the dominant arm hanging to the side. The dominant arm should be straight and relaxed.

The dumbbell is placed in the hand of the dominant arm that is extended toward the floor. The 4 pound dumbbell is used for the females and the 8 pound dumbbell is used for the males. The running stopwatch should be placed in the nondominant hand resting in the lap and facing the dominant side of the body. The technician testing the subject should stand on the side of the dominant arm and place one hand on the dominant bicep and the other hand helping to support the dumbbell. The hand helping to support the dumbbell is then removed and the subject is asked to contract the bicep through the full range of motion until the lower arm touches the hand of the technician on the bicep. This represents one total repetition. If the subject cannot bring the weight through the full range of motion, the test is terminated with a score of zero.

If the practice repetition is complete, the weight is placed on the floor for approximately one minute and again placed in the hand supported by the technician. The technician then instructs the subject to make as many repetitions as possible in thirty seconds. The lower arm must touch the technician's hand (on the bicep) for a complete repetition. 
While watching the stopwatch, the technician instructs the subject to begin (unassisted) and counts the number of repetitions the subject can do in the thirty second period. The technician starts and stops the time interval at a convenient time on the stop watch.

Trials: One thirty second trial.

Scoring: Record the maximum number of complete repetitions in the thirty second interval.

Range of Scores: Zero to forty.

Special Considerations: Subjects should be instructed to breathe normally during the test. The weight should not bounce off the floor. If this is the case, elevate the chair. Subjects should be instructed to stop the test if the subject experiences pain in the tested arm. The technician must determine if the pain is due to a structural condition or the lack of strength. If it is the former, the test is invalid and no score recorded. 
Parameter: Endurance

Test Item: Half mile walk or 880 yard walk

Equipment: Stop watch, measuring tape, and cones

Procedure:

Set-up: The test involves a continuous walk of 880 yards. The person walks around a measured lap until the subject has walked a total of 880 yards. Using a measuring tape of similar device, measure an oval or rectangle of 67 yards or longer. Mark the inside edges of the lap with cones. The lap should be designed with sufficient space to turn; if conducted in a hallway, a minimum length of fifty yards with a width of five feet is recommended. The area should be well lit, the surface non-slippery and level. All obstacles should be removed from the path. Individuals not taking the test should not be allowed to walk onto the course during the test.

Test Administration: Instruct the person to walk the course ( $x$ number of laps) as fast as they feel comfortable; they may not run. Subjects should walk at their own pace independent of the other participants. It is important that the subjects pace themselves so they are able to finish the distance and do not experience discomfort. If an individual is dizzy, lightheaded, nauseous, or experiences any pain, that individual should stop the test immediately and let the technician know. On the signal "Ready, Go," the subject begins at a designated spot and walks the necessary laps until one reaches 880 yards.

Administrative Cues: Screen individuals for cardiovascular or orthopedic contraindications. Give the directions first; start the test with "Ready, Go," and then start the stopwatch. Either the test administrator or assistant counts each subject's number of laps and records the time at the completion of the 880 yards.

Scoring: Record the time to the nearest second.

Approximate range of scores: 7.5 to 12 minutes 
Special considerations:

A. Under the following circumstances, the test administrator should sither discourage or not allow the participant to perform the test without first consulting their physician:

1. Significant orthopedic problems that be aggravated by prolonged continuous walking (8-10 minutes).

2. History of cardiac problems (i.e., recent heart attack, frequent arrhythmia, valvular defects) that can be negatively influenced by exertion.

3. Lightheadedness upon activity or history of uncontrolled hypertension.

B. The walk test should be administered last in the battery of tests.

C. Individuals should practice walking several days prior to the test to determine an appropriate walking pace.

Reprinted with permission from Functional fitness assessment for adults over 60 years (1990). 


\section{APPENDIX D}

\section{AAHPERD FUNCTIONAL FITNESS ASSESSMENT FOR ADULTS OVER 60 YEARS}

Individual Data Coliection Form

Name: Testing Date

Address:

Telephone:

Sex: $F$ M Age (in years) Location:

Test Administrator

Ethnic European-American

Bkgnd Asian American Native American African-American Mexican-American Other

Test Item

Test Trials/score

Trial 1 Trial 2

1. Ponderal Index

(to nearest . 1 of unit)

Final

Recorded

Weight

Score

Height

Ponderal Index

2. Elexibility

Score to .5 in.)

3. Agility/ Denamic Balance

Score seconds and

tenths of seconds

4. ceordination

Score seconds and tenths of seconds

5. Strength

Score of reps. in $30 \mathrm{sec}$. 4 1bs. women, 8 lbs. men

single lift practice

6. Endurence Halk

Time in minutes and seconds 


\section{APPENDIX E}

\section{SENIOR AND COMMUNITY CENTERS USED FOR DATA COLLECTION}

Cupertino Senior Center

21251 Stevens Creek Blvd

Cupertino, CA 95014

Cypress Senior Center

403 S. Cypress Ave

San Jose, CA 95117

Evergreen Community Center

4860 San Felipe Road

San Jose, CA 95135

Gerry Bernhard Senior Center

4375 Payne Ave.

San Jose, CA 95117

Kirk Senior Program

1601 Foxworthy Ave.

San Jose, CA 95118

Life's Garden

450 Old San Francisco Road

Sunnyvale, CA 94086
Plaza Del Rey

1225 Vienna Ave.

Sunnyvale, CA 94086

Saratoga Senior Center

19655 Allendale Ave.

Saratoga, CA 95070

Southside Senior Center

5585 Cottle Road Room 5

San Jose, CA 95123

Sunnyvale Senior Center

820 W. McKinley Ave.

Sunnyvale, CA 94086

Valley Village Center

390 N. Winchester

Santa Clara, CA 95053

Willows Senior Center

2175 Lincoln Ave.

San Jose, CA 95125 


\section{Customer Supplied Stock:}

Please read and sign this form when placing an order on any customer provided stock. This includes, but is not limited to:

- Paper

- Cardstock

- Items to be Laminated

- Items to be Bound

I understand that occasionally circumstances arise beyond the control of Kinko's Copy Center, such as: machine malfunctions, or stock that may become jammed in our high speed copy machines.

By signing this form, I agree to let Kinko's use my stock and understand that it might not run and could become damaged if run through their machines.

I also understand that Kinko's will make every possible attempt to notify me if my stock is not able to run.

Please help us by completing the information below:

Customer Name: Ruth He $\neq$ hes

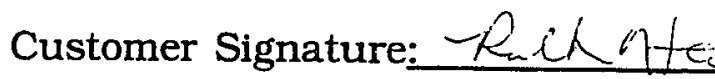

Daytime Phone Number: $378-1713$

Evening Phone Number:

You may call me between the hours of and

Please note any further Instritctions: 